\title{
Selective Inhibition of Trigeminovascular Neurons by Fremanezumab: A Humanized Monoclonal Anti-CGRP Antibody
}

\author{
Agustin Melo-Carrillo, ${ }^{1,2}$ - Rodrigo Noseda, ${ }^{1,2}$ Rony-Reuven Nir, ${ }^{3}{ }^{\circledR}$ Aaron J. Schain, ${ }^{1,2}$ - Jennifer Stratton, ${ }^{4}$ \\ (D)Andrew M. Strassman, ${ }^{1,2}$ and $\mathbb{D}$ Rami Burstein ${ }^{1,2}$ \\ ${ }^{1}$ Department of Anesthesia, Critical Care, and Pain Medicine, Beth Israel Deaconess Medical Center, Boston, Massachusetts 02215, ${ }^{2} \mathrm{Harvard}$ Medical \\ School, Boston, Massachusetts 02115, ${ }^{3}$ Department of Neurology, Rambam Health Care Campus, and Laboratory of Clinical Neurophysiology, Faculty of \\ Medicine, Technion Israel Institute of Technology, Haifa, Israel 3200003, and ${ }^{4}$ Teva Biologics, Redwood City, California 94063
}

\begin{abstract}
A large body of evidence supports an important role for calcitonin gene-related peptide (CGRP) in migraine pathophysiology. This evidence gave rise to a global effort to develop a new generation of therapeutics that inhibit the interaction of CGRP with its receptor in migraineurs. Recently, a new class of such drugs, humanized anti-CGRP monoclonal antibodies (CGRP-mAbs), were found to be effective in reducing the frequency of migraine. The purpose of this study was to better understand how the CGRP-mAb fremanezumab (TEV-48125) modulates meningeal sensory pathways. To answer this question, we used single-unit recording to determine the effects of fremanezumab (30 $\mathrm{mg} / \mathrm{kg}, \mathrm{IV}$ ) and its isotype control Ab on spontaneous and evoked activity in naive and cortical spreading depression (CSD)-sensitized trigeminovascular neurons in the spinal trigeminal nucleus of anesthetized male and female rats. The study demonstrates that, in both sexes, fremanezumab inhibited naive high-threshold (HT) neurons, but not wide-dynamic range trigeminovascular neurons, and that the inhibitory effects on the neurons were limited to their activation from the intracranial dura but not facial skin or cornea. In addition, when given sufficient time, fremanezumab prevents the activation and sensitization of HT neurons by CSD. Mechanistically, these findings suggest that HT neurons play a critical role in the initiation of the perception of headache and the development of cutaneous allodynia and central sensitization. Clinically, the findings may help to explain the therapeutic benefit of CGRP-mAb in reducing headaches of intracranial origin such as migraine with aura and why this therapeutic approach may not be effective for every migraine patient.
\end{abstract}

Key words: allodynia; cortical spreading depression; dorsal horn; headache; migraine; sensitization

Significance Statement

Calcitonin gene-related peptide (CGRP) monoclonal antibodies (CGRP-mAbs) are capable of preventing migraine. However, their mechanism of action is unknown. In the current study, we show that, if given enough time, a CGRP-mAb can prevent the activation and sensitization of high-threshold (central) trigeminovascular neurons by cortical spreading depression, but not their activation from the skin or cornea, suggesting a potential explanation for selectivity to migraine headache, but not other pains, and a predominantly peripheral site of action.

\section{Introduction}

Calcitonin gene-related peptide (CGRP) is expressed in primary afferent neurons that provide sensory innervation to superficial

Received March 1, 2017; revised April 14, 2017; accepted May 18, 2017.

Author contributions: A.M.-C., R. Noseda, R. Nir, A.S., J.S., A.M.S., and R.B. designed research; A.M.-C. and R.B. performed research; A.M.-C., R. Noseda, R. Nir, A.S., and R.B. analyzed data; A.M.-C., A.M.S., and R.B. wrote the paper.

This study was supported by Teva Pharmaceutical Industries and the National Institutes of Health (Grants R37NS079678, R01 NS069847, and R01 NS094198 to R.B.). A.S. was supported by a grant from R. Chemers Neustein.

J.S. is an employee of and R.B. is a consultant to TEVA Pharmaceutical, which holds the patent for treating episodic and chronic migraine with fremanezumab and funded parts of the study. The remaining authors declare no competing financial interests. and deep tissues (Kruger et al., 1989; Silverman and Kruger, 1989). This peptidergic population consists primarily of $A \delta$ - and C-fiber neurons (McCarthy and Lawson, 1990; Lawson et al., 1993; Lawson et al., 1996; Lawson et al., 2002; Ruscheweyh et al., 2007) and is predominantly nociceptive (Lawson et al., 2002).

A large body of evidence supports an important role for CGRP in the pathophysiology of migraine (Hansen and Ashina, 2014; Karsan and Goadsby, 2015; Russo, 2015). First, CGRP is present

Correspondence should be addressed to Rami Burstein, Harvard Medical School, CLS-649, 3 Blackfan Circle, Boston, MA 02115. E-mail: rburstei@bidmc.harvard.edu.

DOl:10.1523/JNEUROSCI.0576-17.2017

Copyright $\odot 2017$ the authors $\quad 0270-6474 / 17 / 377149-15 \$ 15.00 / 0$ 
in the peripheral sensory innervation of the cranial meninges (O'Connor and van der Kooy, 1988; Tsai et al., 1988; Uddman et al., 1989; Keller and Marfurt, 1991; Edvinsson et al., 1998; Edvinsson et al., 2001), the neurons at the origin of a sensory pathway that has been critically implicated in the generation of migraine headache (Moskowitz, 1984; Strassman et al., 1996; Burstein et al., 2015). Second, levels of CGRP are increased in the blood and saliva during migraine attacks (Goadsby et al., 1990; Bellamy et al., 2006b; Cady et al., 2009) and exogenous CGRP administration triggers a delayed migraine-like headache in migraineurs (Hansen et al., 2010). Third, mice with increased expression of the CGRP receptor exhibit photophobia (Recober et al., 2009; Russo et al., 2009; Recober et al., 2010; Kaiser et al., 2012), a characteristic feature of migraine. Fourth, among the most well documented biological effects of anti-migraine agents such as sumatriptan is a suppression of CGRP release, which has been demonstrated in cultured trigeminal ganglion neurons (Durham and Russo, 1999), in meningeal tissue in vitro (Eltorp et al., 2000), in blood measurements during meningeal stimulation in vivo (Buzzi et al., 1991; Goadsby and Edvinsson, 1994), and in saliva measurements during migraine (Bellamy et al., 2006b; Cady et al., 2009). Triptans and other 5HT1D agonists also block the increase in CGRP gene promoter activity in trigeminal ganglion neurons evoked by nitric oxide donors, which are potent headache-triggering agents, as well as other stimuli (Durham et al., 1997; Durham and Russo, 1998, 2003; Durham et al., 2004; Bellamy et al., 2006a).

The evidence supporting the importance of CGRP in migraine gave rise to a worldwide effort to develop a new generation of drugs that reduce the availability of CGRP in migraineurs. Recently, humanized CGRP monoclonal antibodies (CGRP-mAbs) were found to be effective in reducing the frequency of chronic migraine (Dodick et al., 2014a; Dodick et al., 2014b; Bigal et al., 2015a; Bigal et al., 2015b; Sun et al., 2016). However, the mechanisms by which these drugs produce their therapeutic effect and, more broadly, the mechanisms by which CGRP contributes to trigeminal neuron activation and migraine, are not fully understood. To better understand the mechanism of action of antiCGRP antibodies in migraine, we examined their effects on spontaneous and evoked activity of high-threshold (HT) and wide-dynamic range (WDR) trigeminovascular neurons in the medullary and upper cervical dorsal horn in anesthetized male and female rats.

\section{Materials and Methods}

Surgical preparation. Experiments were approved by the Beth Israel Deaconess Medical Center and Harvard Medical School standing committees on animal care and were in accordance with the U.S. National Institutes of Health's Guide for the Care and Use of Laboratory Animals. Male and female Sprague Dawley rats $(250-350 \mathrm{~g})$ were anesthetized with urethane $(0.9-1.2 \mathrm{~g} / \mathrm{kg}$, i.p.). They were fitted with an intratracheal tube to allow artificial ventilation $\left(0.1 \mathrm{~L} / \mathrm{min}\right.$ of $\left.\mathrm{O}_{2}\right)$ and an intrafemoral vein cannula for later infusion of drugs. Rats were placed in a stereotaxic apparatus and core temperature was kept at $37^{\circ} \mathrm{C}$ using a heating blanket. End-tidal $\mathrm{CO}_{2}$ was monitored continuously and kept within physiological range (3.5-4.5 $\left.\mathrm{pCO}_{2}\right)$. Once stabilized, rats were paralyzed with rocuronium bromide $(10 \mathrm{mg} / \mathrm{ml}, 1 \mathrm{ml} / \mathrm{h}$ continuous intravenous infusion) and ventilated. For stimulation of the cranial dura later in the experiment, a $5 \times 5 \mathrm{~mm}$ opening was carefully carved in the parietal and occipital bones in front and behind the lambda suture directly above the left transverse sinus. The exposed dura was kept moist using a modified synthetic interstitial fluid containing the following (in mM): $135 \mathrm{NaCl}$, $5 \mathrm{KCl}, 1 \mathrm{MgCl}_{2}, 5 \mathrm{CaCl}_{2}, 10$ glucose, and 10 HEPES, pH 7.2. For singleunit recording in the spinal trigeminal nucleus, a segment of the spinal cord between the obex and C2 was uncovered from overlying tissues, stripped of the dura mater, and kept moist with mineral oil.
Neuronal identification and selection. To record neuronal activity, a tungsten microelectrode (impedance 3-4 M $\Omega$ ) was lowered repeatedly into the spinal trigeminal nucleus in search of central trigeminovascular neurons receiving convergent input from the dura and facial skin. Trigeminovascular neurons were first identified based on their responses to electrical stimulation of the dura. They were selected for the study if they exhibited discrete firing bouts in response to ipsilateral electrical (0.1-3.0 $\mathrm{mA}, 0.5 \mathrm{~ms}, 0.5 \mathrm{~Hz}$ pulses) and mechanical (with a calibrated von Frey monofilaments) stimulation of the exposed cranial dura and to mechanical stimulation of the facial skin and cornea. Dural receptive fields were mapped by indenting the dura [with the $4.19 \mathrm{~g}$ von Frey hair (VFH) monofilament] at points separated by $1 \mathrm{~mm}$ mediolaterally and rostrocaudally. Points at which dural indentation produced a response in $\geq 50 \%$ of the trials were considered inside the neuron's receptive field. Cutaneous receptive fields were mapped by applying innocuous and noxious mechanical stimulation to all facial skin areas and the cornea as described previously (Burstein et al., 1998). An area was considered outside the receptive field if no stimulus produced a response in $\geq 50 \%$ of the trials. Responses to mechanical stimulation of the skin were determined by applying brief (10 s) innocuous and noxious stimuli to the most sensitive portion of the cutaneous receptive field. Innocuous stimuli consisted of slowly passing a soft bristled brush across the cutaneous receptive field (one $5 \mathrm{~s}$ brush stroke from caudal to rostral and one $5 \mathrm{~s}$ brush stroke from rostral to caudal) and pressure applied with a loose arterial clip. Noxious stimuli consisted of pinch with a strong arterial clip ( $\mathrm{Pa}-$ lecek et al., 1992; Dado et al., 1994; Burstein et al., 1998). More intense or prolonged stimuli were not used to avoid inducing prolonged changes in spontaneous neuronal discharge or response properties. Responses to mechanical stimulation of the cornea consisted of gentle and slow brushing strokes with a thin paintbrush ( $\sim 10$ hair follicles). Two classes of neurons were thus identified: WDR neurons (incrementally responsive to brush, pressure, and pinch) and HT neurons (unresponsive to brush). A real-time waveform discriminator was used to create and store a template for the action potential evoked in the neuron under study by electrical pulses on the dura; spikes of activity matching the template waveform were acquired and analyzed online and offline using Spike 2 software (CED).

Induction and recording of cortical spreading depression. Cortical spreading depression (CSD) was induced mechanically by inserting a glass micropipette (tip diameter $25 \mu \mathrm{m}$ ) 1 mm into the visual cortex for $10 \mathrm{~s}$. At a propagation rate of $3-5 \mathrm{~mm} / \mathrm{min}$, a single wave of CSD was expected to enter the neuronal receptive field within 1-2 min of cortical stimulation. For verification of CSD, cortical activity was recorded (ECG) with a glass micropipette ( $0.9 \%$ saline, $\sim 1 \mathrm{M} \Omega, 7 \mu \mathrm{m}$ tip) placed just below the surface of the cerebral cortex $(\sim 100 \mu \mathrm{m})$. The ECG electrode was positioned $\sim 6 \mathrm{~mm}$ anterior to the visual cortex.

Treatment with the monoclonal anti-CGRP antibody fremanezumab (TEV-48125). Fremanezumab (formerly TEV-48125/LBR-101/RN-307; TEVA Pharmaceutical Industries) is a humanized CGRP-mAb. It was diluted in saline to a final dose of $30 \mathrm{mg} / \mathrm{kg}$ and administered intravenously (bolus injection, total volume $0.6-0.7 \mathrm{ml}$ ). A corresponding human IgG2 isotype control antibody (isotype-conAb) was also diluted in saline to a final dose of $30 \mathrm{mg} / \mathrm{kg}$ and administered intravenously (bolus injection, total volume $1.6-2.0 \mathrm{ml}$ ).

Experimental protocol. The experimental protocol included two parts. The first part was designed to compare CGRP-mAb versus isotypeconAb effects on spontaneous and induced activity of naive trigeminovascular neurons and the second part was designed to test CGRP-mAb versus isotype-conAb effects on the activation and sensitization of trigeminovascular neurons by CSD. Both parts included sampling of WDR and HT neurons in male and female rats. In the first part, the baseline neuronal profile was established by mapping the dural, cutaneous, and corneal receptive field; measuring responses (mean spikes/s) to mechanical stimulation of the dura (with a fixed force), skin (brush, pressure, pinch), and cornea (brush); and measuring spontaneous firing rate (recorded over $30 \mathrm{~min}$ before treatment). Once the baseline was established, CGRP-mAb or isotype-conAb were administered and receptive fields were remapped; neuronal responses to stimulation of the dura, skin, and cornea were reexamined; and the spontaneous activity rate was resa- 
A

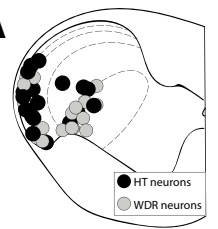

Male

\section{CGRP mAb}

B

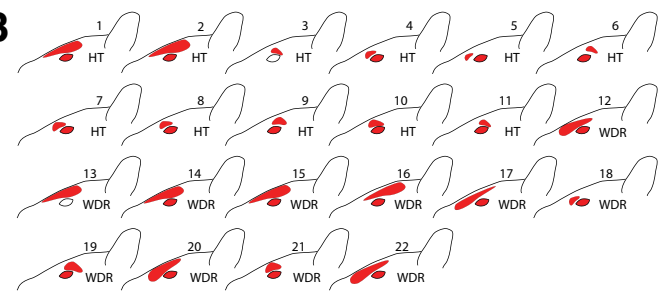

C

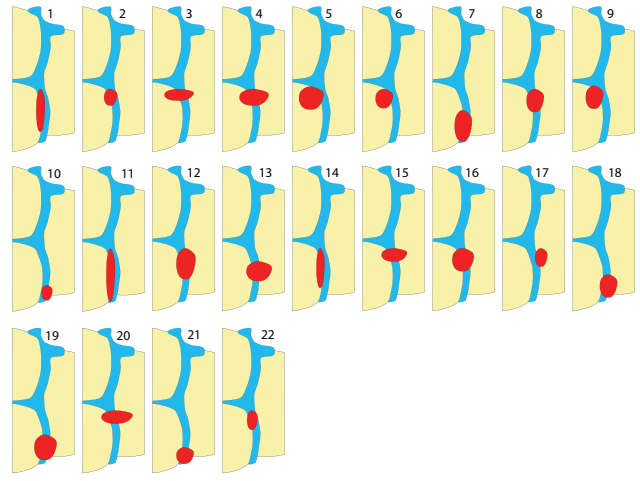

Isotype (control)

D

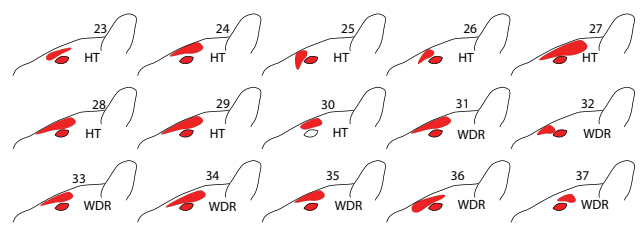

E

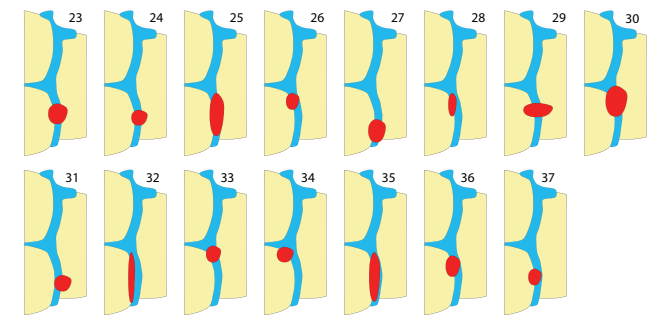

$\mathbf{F}$

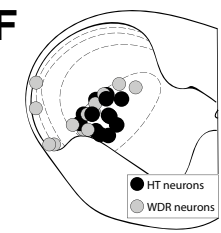

\section{Female}

\section{CGRP mAb}

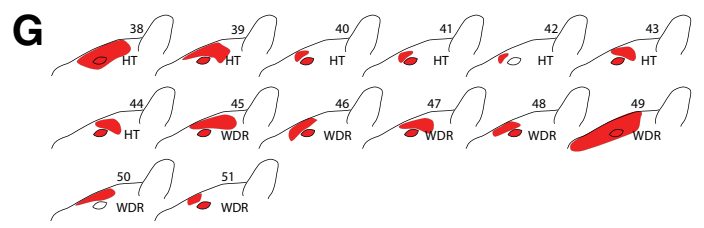

H
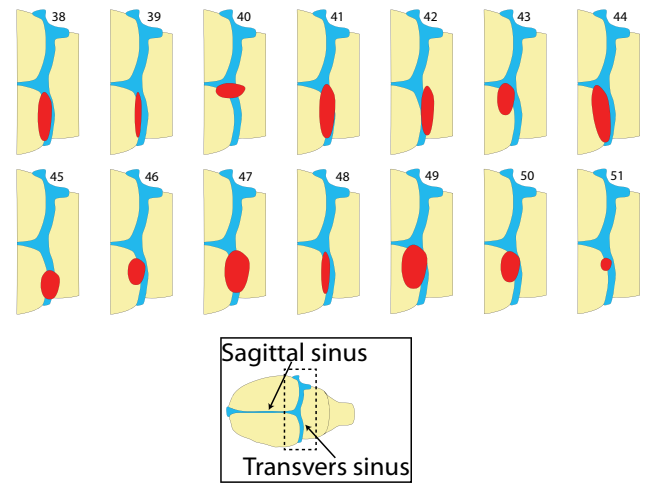

Isotype (control)

\section{I}

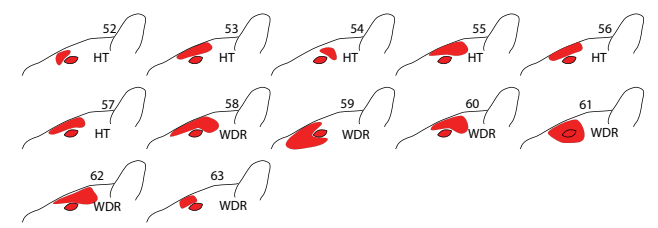

J

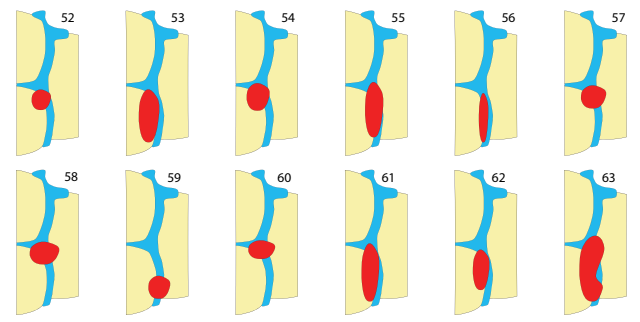

Figure 1. Recording sites $(\boldsymbol{A}, \boldsymbol{F})$, facial receptive fields $(\boldsymbol{B}, \boldsymbol{D}, \boldsymbol{G}, \boldsymbol{I})$, and dural receptive fields $(\boldsymbol{C}, \boldsymbol{E}, \boldsymbol{H}, \boldsymbol{J})$ of each of the 63 trigeminovascular neurons tested for effects of the $(G R P-\mathrm{mAb}(\boldsymbol{A}-\boldsymbol{C}, \boldsymbol{F}-\boldsymbol{H}$, $n=36)$ or the isotype-conAb $(\boldsymbol{D}, \boldsymbol{E}, \boldsymbol{I}, \boldsymbol{J}, n=27)$ in male and female rats. $\boldsymbol{A}, \boldsymbol{F}$, Recording sites plotted on a representative transverse section through the first cervical segment. Black and grey circles represent HT and WDR neurons, respectively. $\boldsymbol{B}, \boldsymbol{D}, \boldsymbol{G}, \boldsymbol{I}$, Most sensitive regions of cutaneous (i.e., where brush, pressure, and pinch were applied) and corneal receptive fields. $\boldsymbol{C}, \boldsymbol{E}, \boldsymbol{H}, \boldsymbol{J}, \mathrm{Mechanically}$ sensitive receptive fields on the dura, which were all on or around the transverse sinus. The portion of the dura shown in the receptive field drawings is outlined by the dashed line in the inset in $\boldsymbol{H}$. All dural and facial receptive fields were ipsilateral to the recorded neuron.

mpled at 1,2,3, and $4 \mathrm{~h}$ after treatment. The resulting values for each measure were then compared with the respective baseline values obtained before treatment. In the second part, CSD was induced $4 \mathrm{~h}$ after administration of CGRP-mAb or isotype-conAb and, $2 \mathrm{~h}$ later (i.e., $6 \mathrm{~h}$ after treatment), receptive field size, spontaneous activity rate, and response magnitude to stimulation of the dura, skin, and cornea were measured again. The resulting post-CSD values for each measure were then compared with the respective pre-CSD values obtained at the $4 \mathrm{~h}$ posttreatment time. This part was initiated only in cases in which the physiological condition of the rats (heart rate, blood pressure, respira- tion, end-tidal $\mathrm{CO}_{2}$ ) and the neuronal isolation signal (signal-to-noise ratio $\geq 1: 3$ ) were stable at the $4 \mathrm{~h}$ posttreatment time point.

At the conclusion of each experiment, a small lesion was produced at the recording site (anodal DC of $15 \mu \mathrm{A}$ for $15 \mathrm{~s}$ ) and its localization in the dorsal horn was determined postmortem using histological analysis as described previously (Zhang et al., 2011). Only one neuron was studied in each animal.

Data analysis. To calculate the response magnitude to each stimulus, the mean firing frequency occurring before the onset of the first stimulus (30 min for spontaneous activity, $10 \mathrm{~s}$ for mechanical stimulation of the 


\section{CGRP mAb}

A

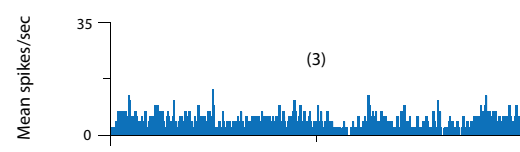

$1 \mathrm{~h}$

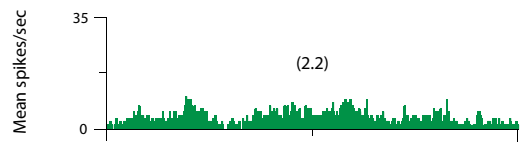

$2 \mathrm{~h}$

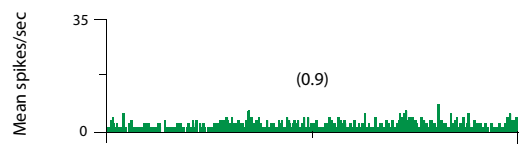

$3 \mathrm{~h}$

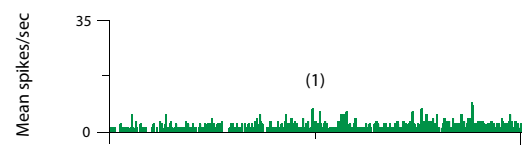

$4 \mathrm{~h}$
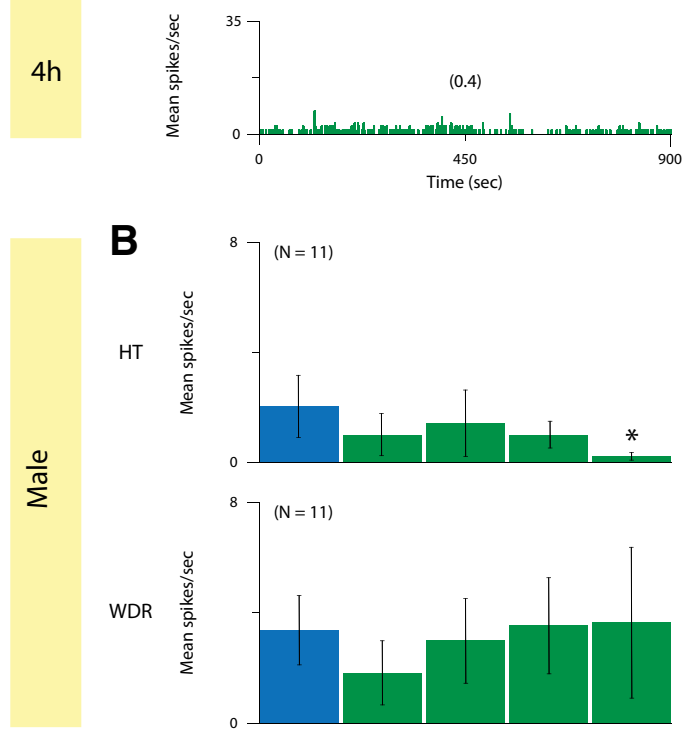

B

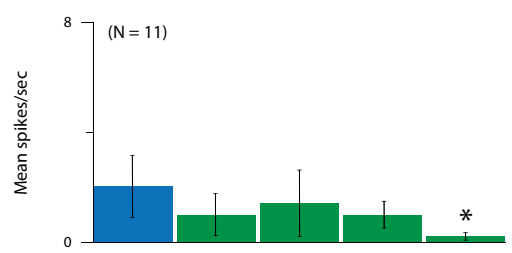

WDR

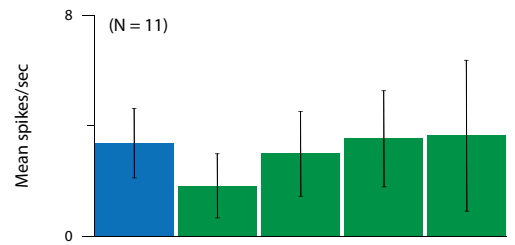

C

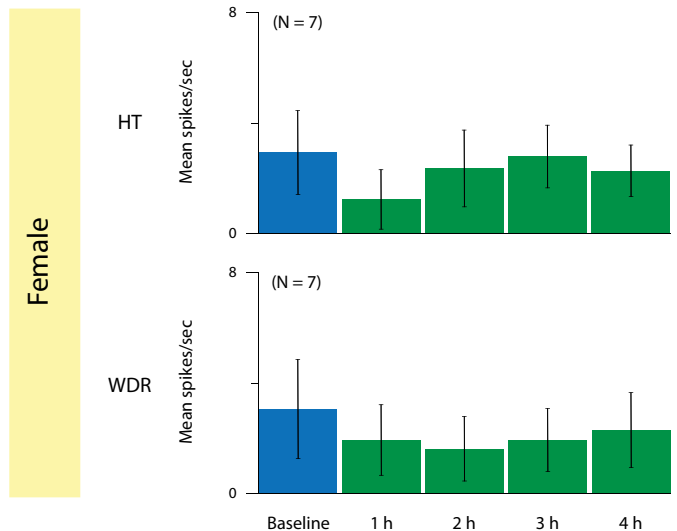

D
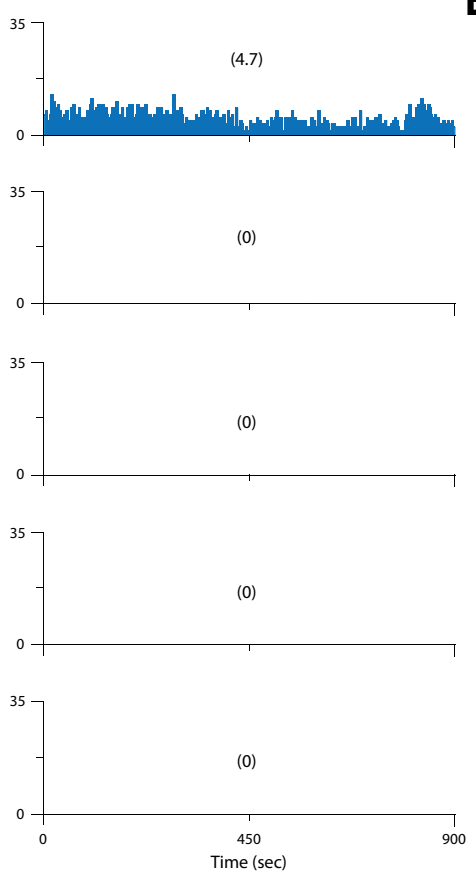

\section{Isotype}

E
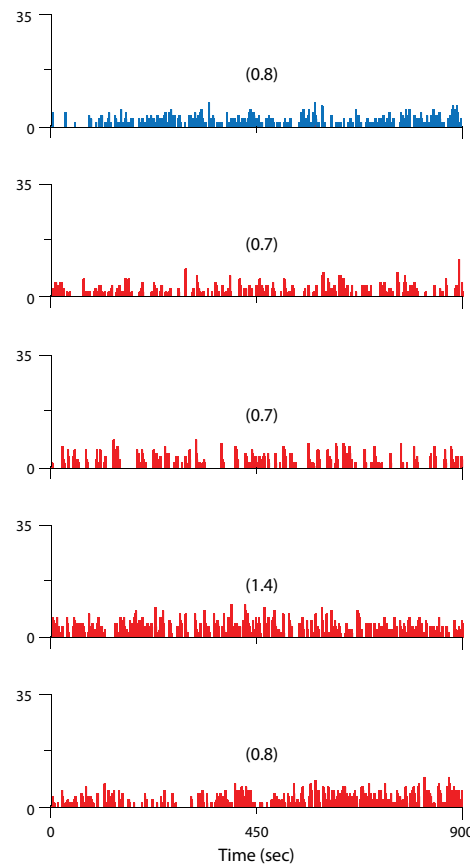

F

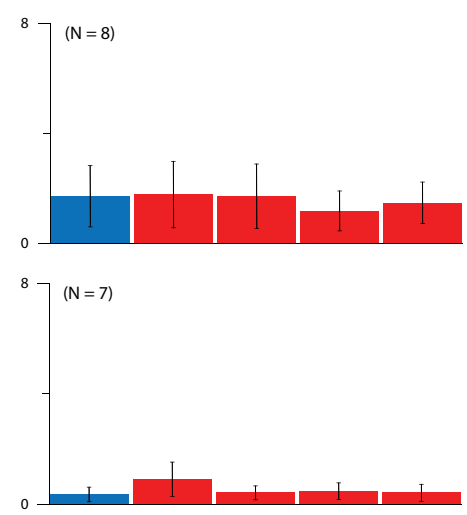

G
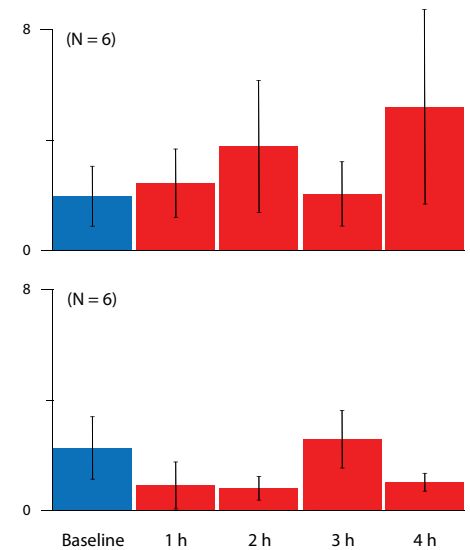

Figure 2. Effect of CGRP-mAb $(\boldsymbol{A}-\boldsymbol{D})$ and isotype-conAb $(\boldsymbol{E}-\boldsymbol{G})$ on spontaneous activity of trigeminovascular neurons in male and female rats. $\boldsymbol{A}, \boldsymbol{D}, \boldsymbol{E}$, Plots of spontaneous discharge rate recorded at baseline (BL) and at $1-4 \mathrm{~h}$ after $(G R P-m A b(A, D)$ or isotype-conAb $(E)$ administration to $\mathrm{HT}$ neurons. Numbers in parentheses show the mean discharge rate for the $15 \mathrm{~min}$ sampling period at each time point. Bin width $=1 \mathrm{~s} . \boldsymbol{B}, \boldsymbol{C}$, Histograms showing mean ( \pm SE) spontaneous discharge of HT and WDR neurons recorded at baseline and $1-4 \mathrm{~h}$ after (GRP-mAb administration in male $(\boldsymbol{B})$ and female $(\boldsymbol{C})$ rats. $\boldsymbol{F}, \mathbf{G}$, Histograms showing mean ( \pm SE) spontaneous discharge of $\mathrm{HT}$ and WDR neurons recorded at baseline and $1-4 \mathrm{~h}$ after isotype-conAb administration in male $(\boldsymbol{F})$ and female (G) rats. ${ }^{*} p<0.05$ compared with baseline. Numbers in parentheses in $\boldsymbol{B}, \boldsymbol{C}, \boldsymbol{F}$, and $\boldsymbol{G}$ depict the number of neurons in each group. Note that the CGRP-mAb reduced baseline spontaneous activity in HT but not WDR neurons (male only). 


\section{CGRP mAb}

A

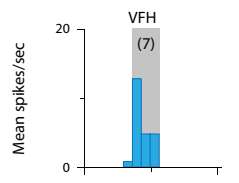

$1 \mathrm{~h}$

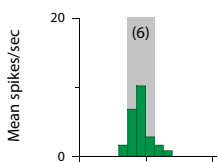

$2 \mathrm{~h}$

$3 h$

$4 \mathrm{~h}$
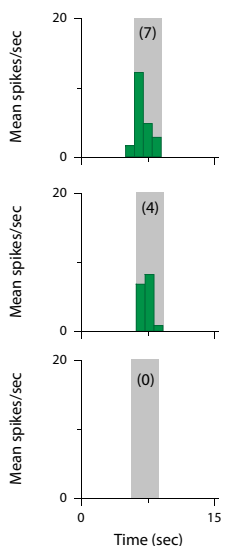

B

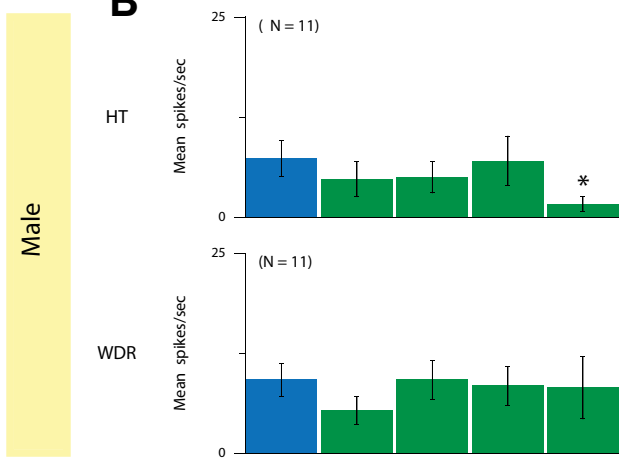

C
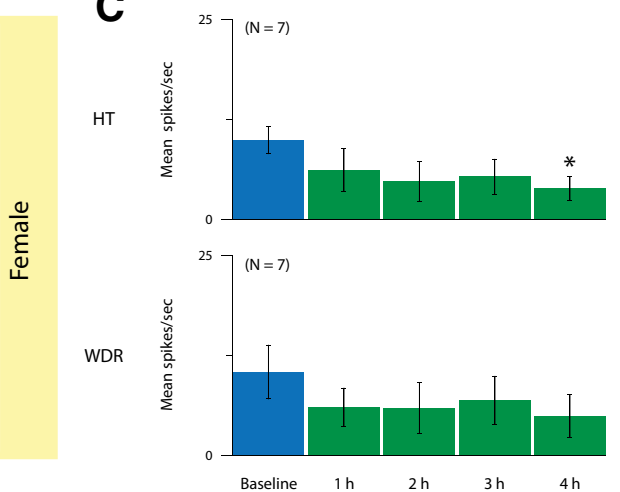

\section{Isotype}

D
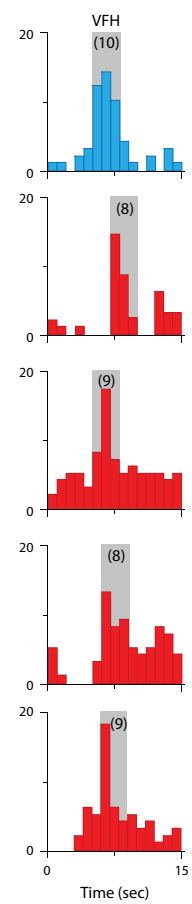

E
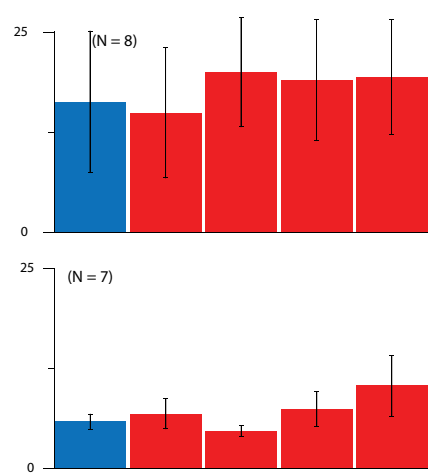

$\mathbf{F}$
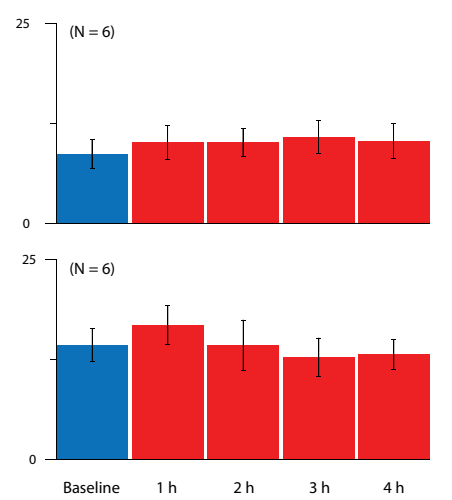

Figure 3. Effect of CGRP-mAb $(\boldsymbol{A}-\boldsymbol{C})$ and isotype-conAb $(\boldsymbol{D}-\boldsymbol{F})$ on response of trigeminovascular neurons to dural indentation in male and female rats. $\boldsymbol{A}, \boldsymbol{D}$, Responses to indentation of the dura with a VFH $(4.19 \mathrm{~g})$ at baseline (BL) and at $1-4 \mathrm{~h}$ after CGRP-mAb $(\boldsymbol{A})$ or isotype-conAb $(\boldsymbol{D})$ administration to $\mathrm{HT}$ neurons. Numbers in parentheses show the mean discharge rate during the stimulus. Bin width $=1 \mathrm{~S} . \boldsymbol{B}, \boldsymbol{C}$, Mean ( \pm SE) discharge rates in response to dural stimulation at baseline and $1-4 \mathrm{~h}$ after drug administration for the entire sample of neurons that received CGRP-mAb in male $(\boldsymbol{B})$ and female $(\boldsymbol{C})$ rats. $\boldsymbol{E}, \boldsymbol{F}$, Mean $( \pm S E)$ discharge rates in response to dural stimulation at baseline and $1-4 \mathrm{~h}$ after drug administration for the entire sample of neurons that received isotype-conAb in male $(\boldsymbol{E})$ and female $(\boldsymbol{F})$ rats. ${ }^{*} p<0.05$ compared with baseline. Numbers in parentheses in $\boldsymbol{B}, \boldsymbol{C}$, $\boldsymbol{E}$, and $\boldsymbol{F}$ depict the number of neurons in each group. Note that, in both sexes, CGRP-mAb reduced responsiveness to mechanical stimulation of the dura in HT but not WDR neurons.

dura, skin, and cornea) was subtracted from the mean firing frequency that occurred throughout the duration of each stimulus. In the first part of the study, corresponding values for each measure (determined at 1, 2, 3, and $4 \mathrm{~h}$ after treatment) were compared with the respective baseline values obtained before CGRP-mAb or isotype-conAb administration. In the second part of the study, resulting values for each measure (determined $2 \mathrm{~h}$ after CSD induction) were compared with the respective values obtained before CSD induction in the two treatment groups (CGRP-mAb and isotypecon $\mathrm{Ab})$. A neuron was considered activated when its mean firing rate after CSD exceeded its mean baseline activity by 2 SDs of that mean for a period $>10 \mathrm{~min}$, which translated to $\geq 33 \%$ increase in activity. A neuron was considered sensitized if, $2 \mathrm{~h}$ after occurrence of CSD, it exhibited enhanced responses to at least 3 of the following 5 stimuli: dural indentation, brushing, pressuring or pinching the skin, and brushing the cornea. Mean firing rates of respective values were compared using nonparametric statistics (Wilcoxon signed-ranks test). Two-tailed level of significance was set at 0.05 .

\section{Results}

The database for testing CGRP-mAb versus isotype-conAb effects on spontaneous and induced activity of naive trigeminovascular neurons consists of 63 neurons. Of these, 31 were classified as WDR and 32 as HT. Of the 31 WDR neurons, 18 (11 in males, 7 in females) were tested before and after administration of the CGRP$\mathrm{mAb}$ and 13 (7 in males, 6 in females) were tested before and after administration of the isotype-conAb. Of the $32 \mathrm{HT}$ neurons, 18 (11 in males, 7 in female) were tested before and after administration of the CGRP-mAb and 14 ( 8 in males, 6 in females) were tested before and after administration of the isotype-conAb.

The database for testing CGRP-mAb versus isotype-conAb effects on the activation and sensitization of the neurons by CSD consists of 50 neurons. Of these, 23 were classified as WDR and 27 as HT. Of the 23 WDR neurons, 13 (7 in males, 6 in females) were tested in the CGRP-mAbtreated animals and 10 (5 in males, 5 in females) in the isotype-conAb-treated animals. Of the 27 HT neurons, 14 (8 in males, 6 in female) were tested in the CGRP-mAb-treated animals and 13 (7 in males, 6 in females) in the isotype-conAbtreated animals.

\section{Recording sites, receptive fields, and neuronal classes}

Recording site, maps of dural and cutaneous receptive fields, and cell types did not differ between neurons tested for CGRP- 


\section{CGRP mAb}

A

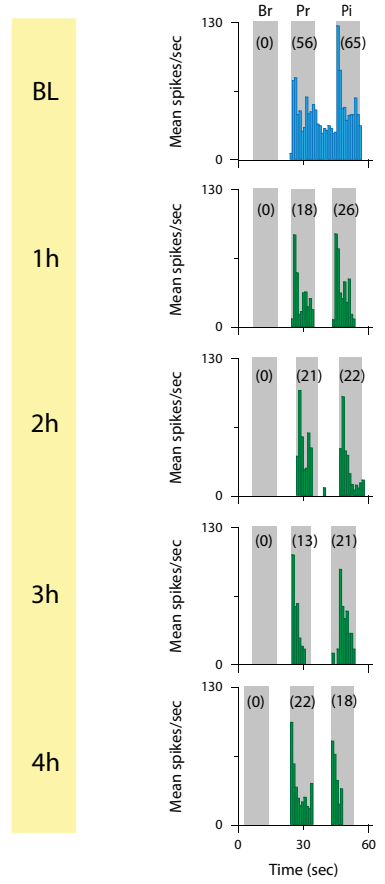

B

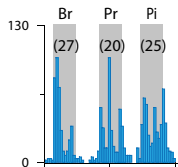

130

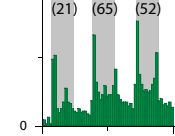

${ }^{130}$

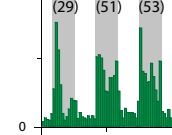

130 7. (28) (55) (56)

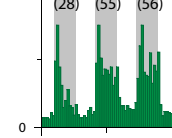

$\left.{ }^{130}\right]$ (26) (54) (57)

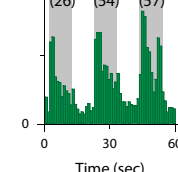

Isotype

$\mathbf{E}$
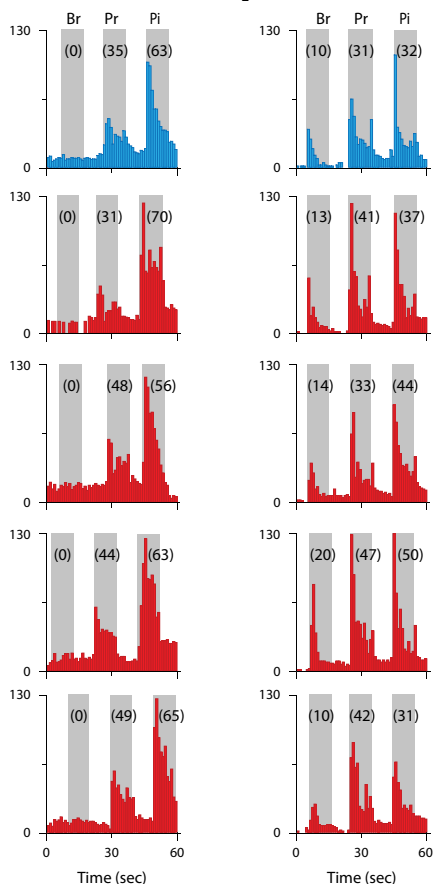

$\mathbf{F}$

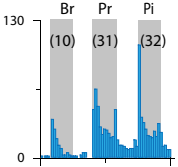

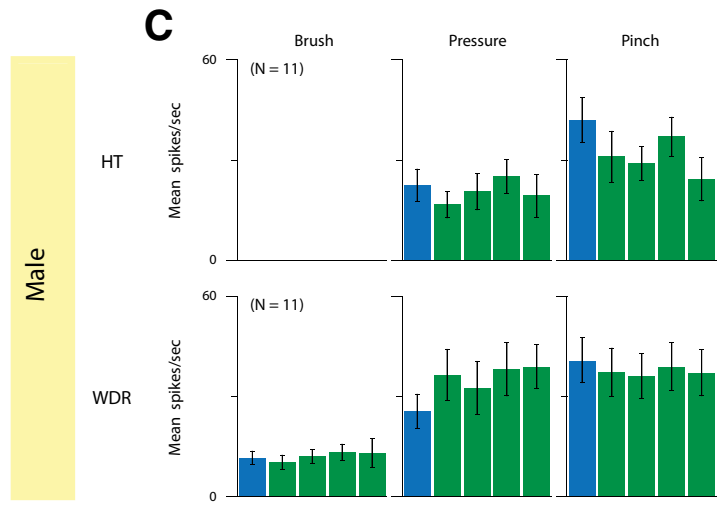
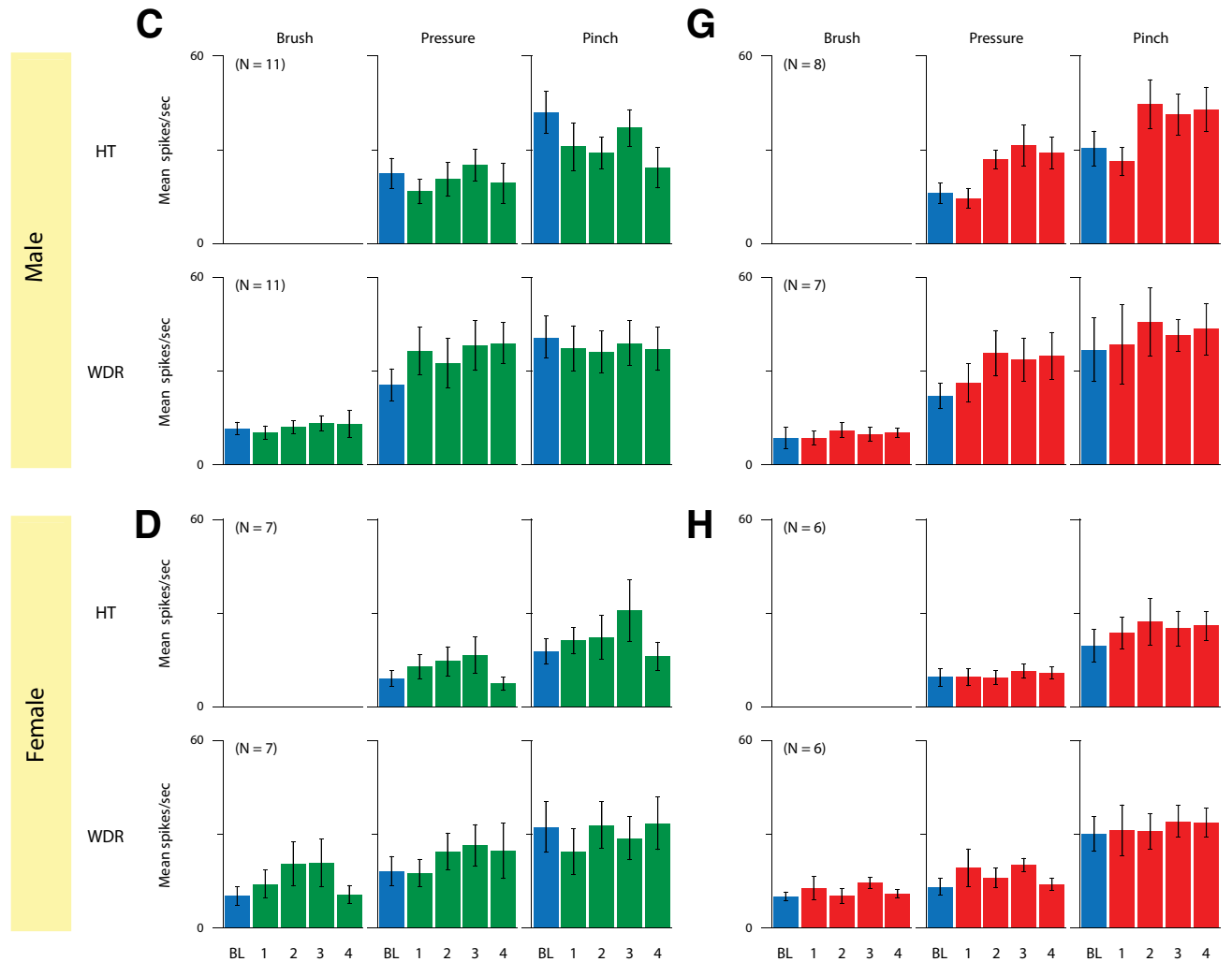

Figure 4. Effect of GGR-mAb $(\boldsymbol{A}-\boldsymbol{D})$ and isotype-conAb $(\boldsymbol{E}-\boldsymbol{H})$ on response of central trigeminovascular neurons to innocuous and noxious mechanical stimulation of cutaneous receptive fields of male and female rats. $A, B, E, F$, Responses to mechanical stimulation of the cutaneous receptive fields of $H T(A, E)$ and WDR $(B, F)$ with brush, pressure, and pinch at baseline (BL) and at $1-4 \mathrm{~h}$ after CGRP-mAb or isotype-conAb administration. Numbers in parentheses show the mean discharge rate during each stimulus. Bin width $=1 \mathrm{~s}$. $C, D$, Mean $( \pm S E)$ discharge rates in response to cutaneous stimulation at baseline and $1-4 \mathrm{~h}$ after drug administration for the entire sample of neurons that received $(\mathrm{GRP}-\mathrm{mAb}$ in male $(\boldsymbol{C})$ and female $(\boldsymbol{D})$ rats. $\boldsymbol{G}, \boldsymbol{H}, \mathrm{Mean}( \pm \mathrm{SE})$ discharge rates in response to cutaneous stimulation at baseline and $1-4 \mathrm{~h}$ after drug administration for the entire sample of neurons that received isotype-conAb in male $(\boldsymbol{G})$ and female $(\boldsymbol{H})$ rats. Numbers in parentheses in $\mathbf{C}, \mathbf{D}, \mathbf{G}$, and $\boldsymbol{H}$ depict the number of neurons in each group. Note that CGRP-mAb did not reduce responsiveness to innocuous and noxious mechanical stimulation of the skin in either sex or class of neurons. 


\section{CGRP mAb}

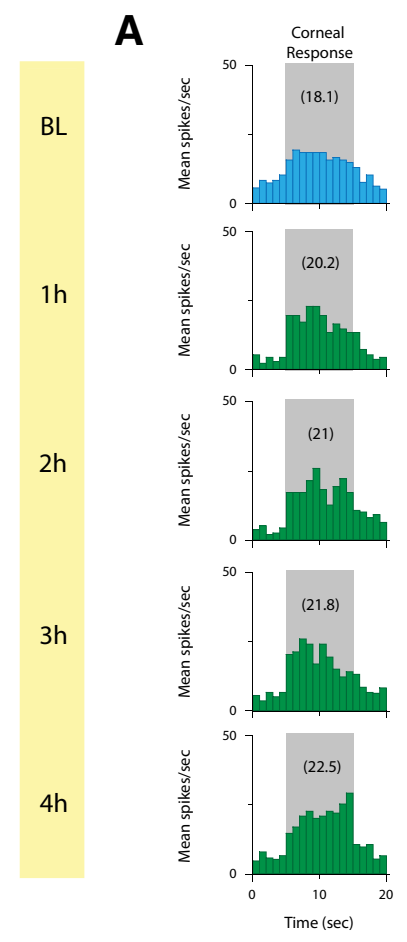

B
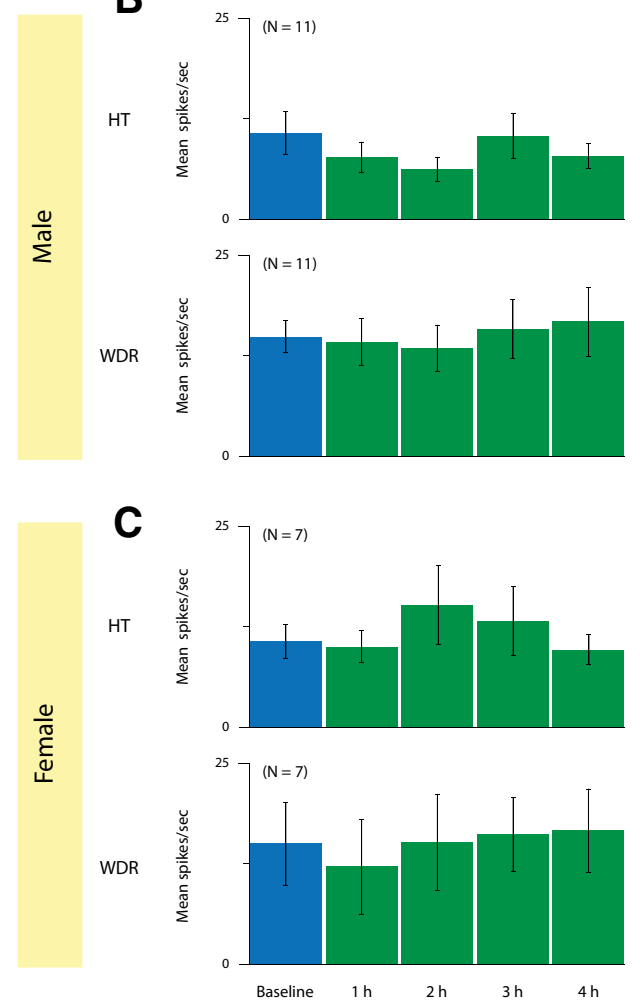

\section{Isotype}

D
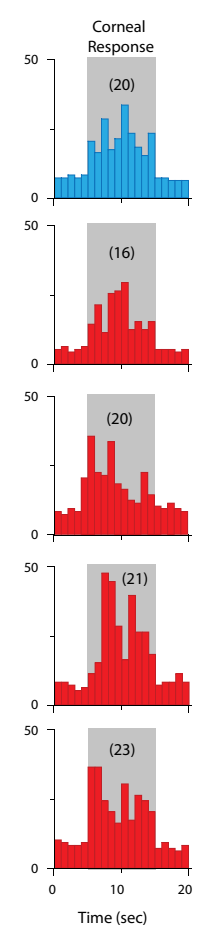

E
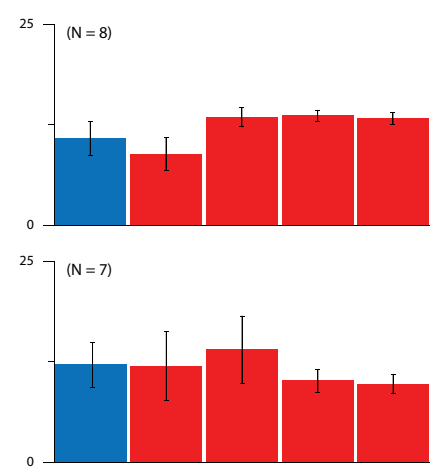

$\mathbf{F}$
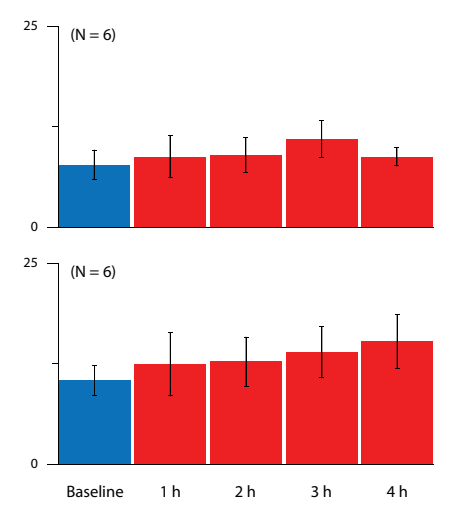

Figure 5. Effect of CGRP-mAb $(\boldsymbol{A}-\boldsymbol{C})$ and isotype-conAb $(\boldsymbol{D}-\boldsymbol{F})$ on response of central trigeminovascular neurons to mechanical stimulation of the cornea in male and female rats. $A, D$, Responses to mechanical stimulation of the cornea by gentle brushing at baseline (BL) and at $1-4 \mathrm{~h}$ after CGRP-mAb $(\boldsymbol{A})$ or isotype-conAb $(\boldsymbol{D})$ administration to $\mathrm{HT}$ neurons. Numbers in parentheses show the mean discharge rate during each stimulus. Bin width $=1$ S. $B, C$, Mean $( \pm S E)$ discharge rates in response to cornea stimulation at baseline and $1-4 \mathrm{~h}$ after drug administration for the entire sample of neurons that received CGRP-mAb in male (B) and female $(\boldsymbol{C})$ rats. $\boldsymbol{E}, \boldsymbol{F}$, Mean ( \pm SE) discharge rates in response to cornea stimulation at baseline and $1-4 \mathrm{~h}$ after drug administration for the entire sample of neurons that received isotype-conAb in male $(\boldsymbol{E})$ and female $(\boldsymbol{F})$ rats. Numbers in parentheses in $\boldsymbol{B}, \boldsymbol{C}, \boldsymbol{E}$, and $\boldsymbol{F}$ depict the number of neurons in each group. Note that CGRP-mAb did not reduce responsiveness to mechanical stimulation of the cornea in either sex or class of neurons.

$\mathrm{mAb}$ and those tested for the isotypeconAb (Fig. 1). All identified recording sites were localized in laminae I-II and IV-V of the first cervical segment of the spinal cord and the caudal part of nucleus caudalis. In all cases, the most sensitive area of the dural receptive field was along the transverse sinus and the most sensitive area of the cutaneous receptive field was around the eye, involving the cornea in $>90 \%$ of the cases.

\section{Spontaneous activity of naive central trigeminovascular neurons}

In male rats, intravenous administration of the CGRP-mAb reduced the spontaneous activity of the HT but not the WDR neurons (Fig. $2 A, B$ ). In the HT group, neuronal firing decreased within $3-4 \mathrm{~h}$ by $90 \%$ ( $p=0.040$ ). Occasionally, the firing rate of some HT neurons decreased within 1-2 $\mathrm{h}$ after the intravenous administration of the CGRP-mAb (Fig. 2D). In contrast, intravenous administration of the isotypeconAb did not alter the spontaneous activity of either group of neurons (Fig. 2E,F).

In females, unlike in males, intravenous administration of the CGRP-mAb did not reduce the spontaneous activity of HT or WDR neurons (Fig. 2C). Similarly, intravenous administration of the isotypeconAb did not alter the spontaneous activity of either group of neurons (Fig. $2 G$ ). Critically, the baseline (i.e., before any treatment) spontaneous firing rate of HT and WDR neurons did not differ between the male and the female rats $(p=0.14)$. For the HT neurons, mean spikes/s before any treatment was $1.7 \pm 1.1$ in the male versus $1.9 \pm 1.0$ in the female $(p=0.55)$. For the WDR neurons, mean spikes/s before any treatment was $0.3 \pm 0.6$ in the male versus $2.2 \pm 1.1$ in the female ( $p=$ $0.16)$.

\section{Sensitivity of naive central trigeminovascular neurons to dural indentation}

In both male and female rats, intravenous administration of the CGRP-mAb reduced the sensitivity to mechanical stimulation of the dura in the HT but not the WDR neurons (Fig. $3 A-C$ ). In males, the firing of HT neurons decreased by $75 \%$ $(p=0.047)$, whereas, in females, it decreased by $61 \%(p=0.017)$. Regardless of the sex, intravenous administration of the isotype-conAb did not alter the sensitivity to dural stimulation in either group of neurons (Fig. 3D-F). 


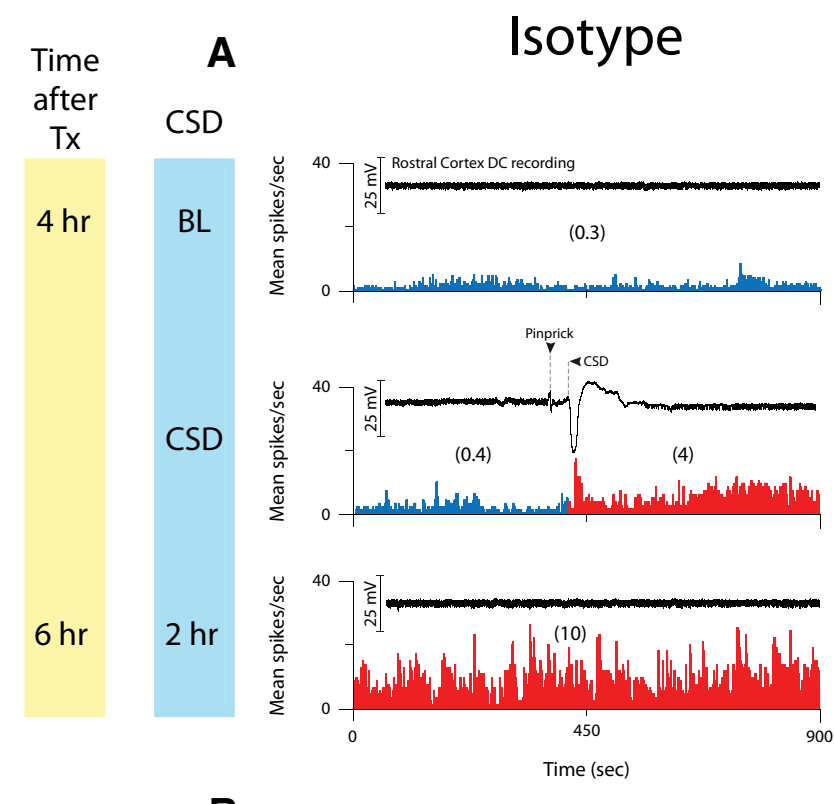

D $\quad$ CGRP mAb
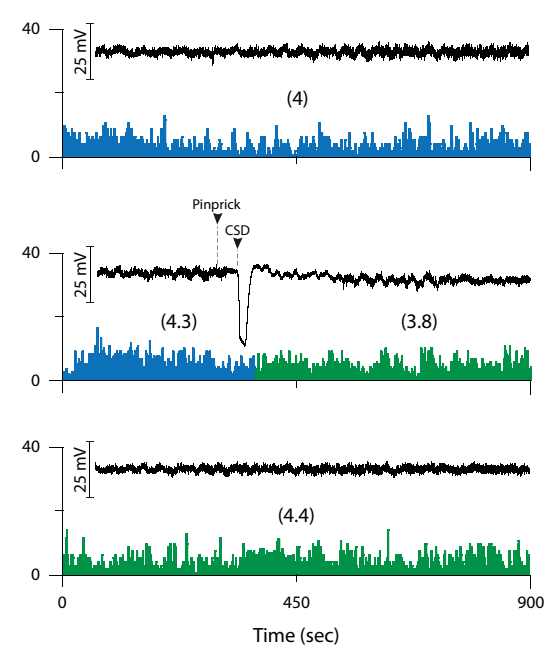

B

E
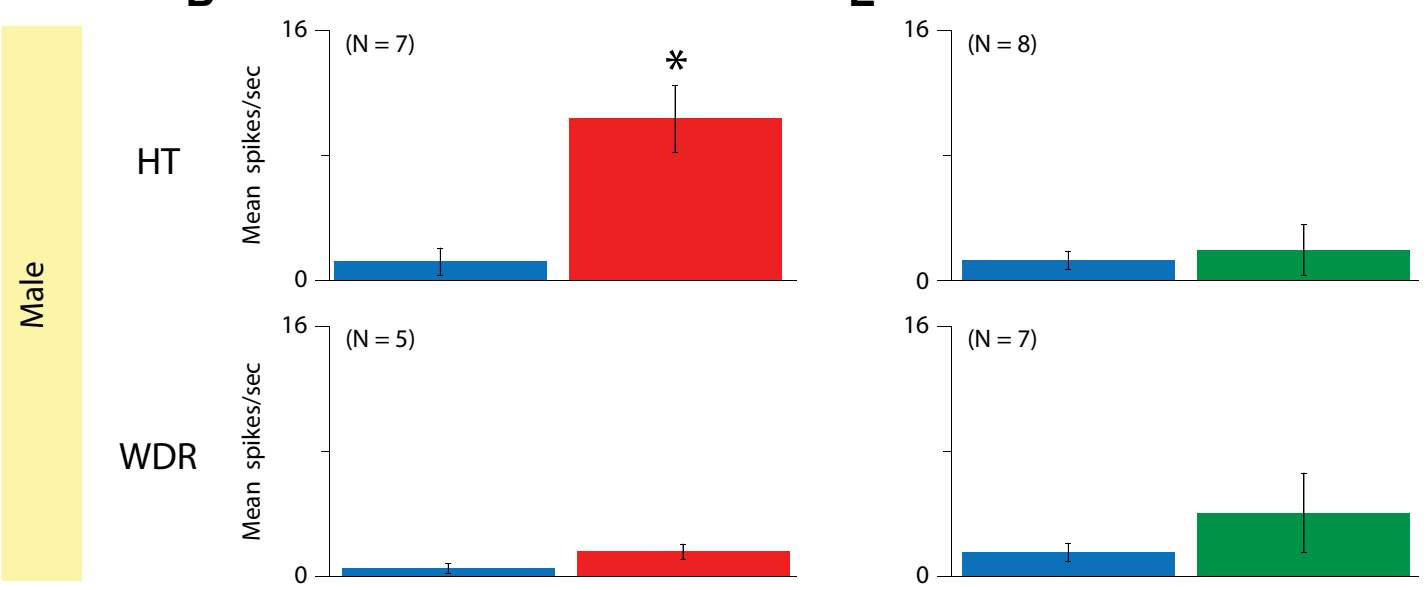

C

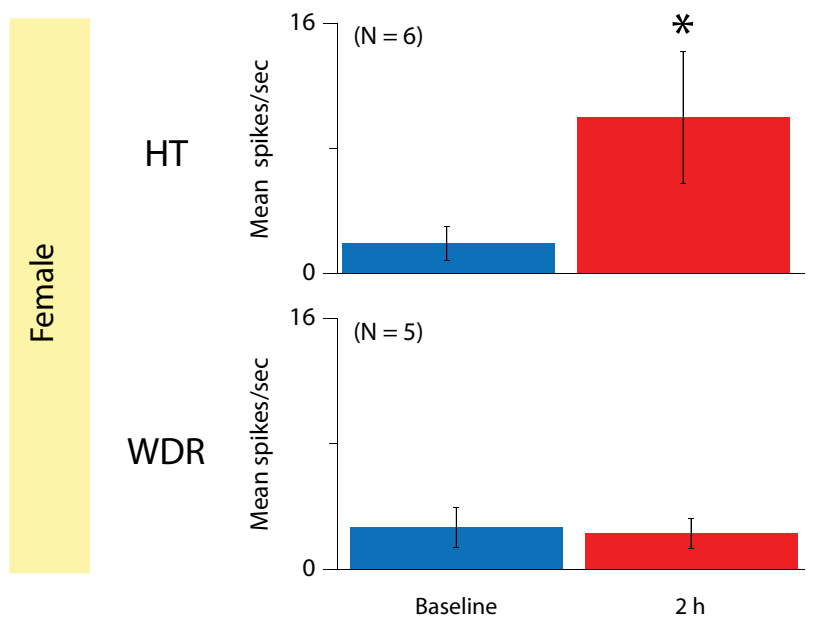

$\mathbf{F}$

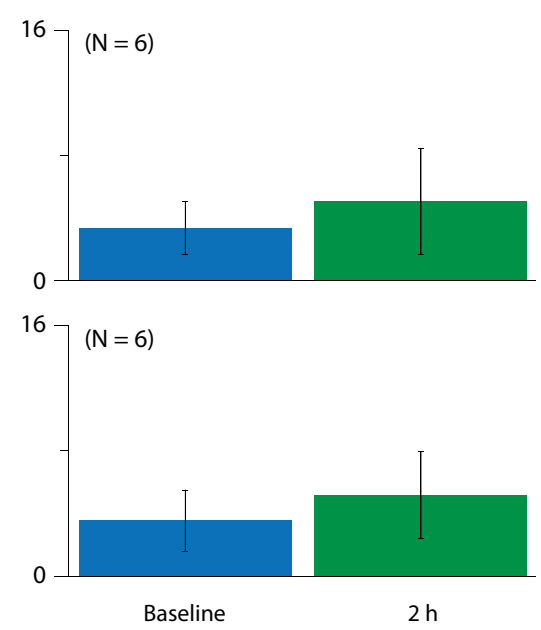

Figure 6. Effect of isotype-conAb $(\boldsymbol{A}-\boldsymbol{C})$ and $C G R P-m A b(D-F)$ on activation of trigeminovascular neurons by CSD. CSD was induced $4 \mathrm{~h}$ after drug treatment. $A, D$, Discharge of trigeminovascular neurons before CSD induction (top), during CSD induction (middle), and $2 \mathrm{~h}$ after CSD (bottom) in $2 \mathrm{HT}$ neurons that received isotype-conAb (A) or CGRP-mAb (D) $4 \mathrm{~h}$ before CSD induction. Bin width $=1 \mathrm{~s} . \boldsymbol{B}, \boldsymbol{C}$, Mean $( \pm \mathrm{SE})$ discharge rates for the entire sample of $\mathrm{HT}$ and WDR trigeminovascular neurons that were tested for CSD responses after isotype-conAb administration in male ( $\boldsymbol{B}$ ) and female $(\boldsymbol{C})$ rats. $\boldsymbol{E}, \boldsymbol{F}$, Mean ( \pm SE) discharge rates for the entire sample of $H$ T and WDR trigeminovascular neurons that were tested for CSD responses after (GRP-mAb administration in male (E) and female $(\boldsymbol{F})$ rats. Discharge is shown at baseline ( $4 \mathrm{~h}$ after drug treatment, before $C S D$ induction) and $2 \mathrm{~h}$ after $C S D .{ }^{*} p<0.05$ compared with baseline. Numbers in parentheses in $\boldsymbol{B}, \boldsymbol{C}, \boldsymbol{E}$, and $\boldsymbol{F}$ depict the number of neurons in each group. Note that, in both sexes, CGRP-mAb prevented the activation of HT trigeminovascular neurons by CSD. 


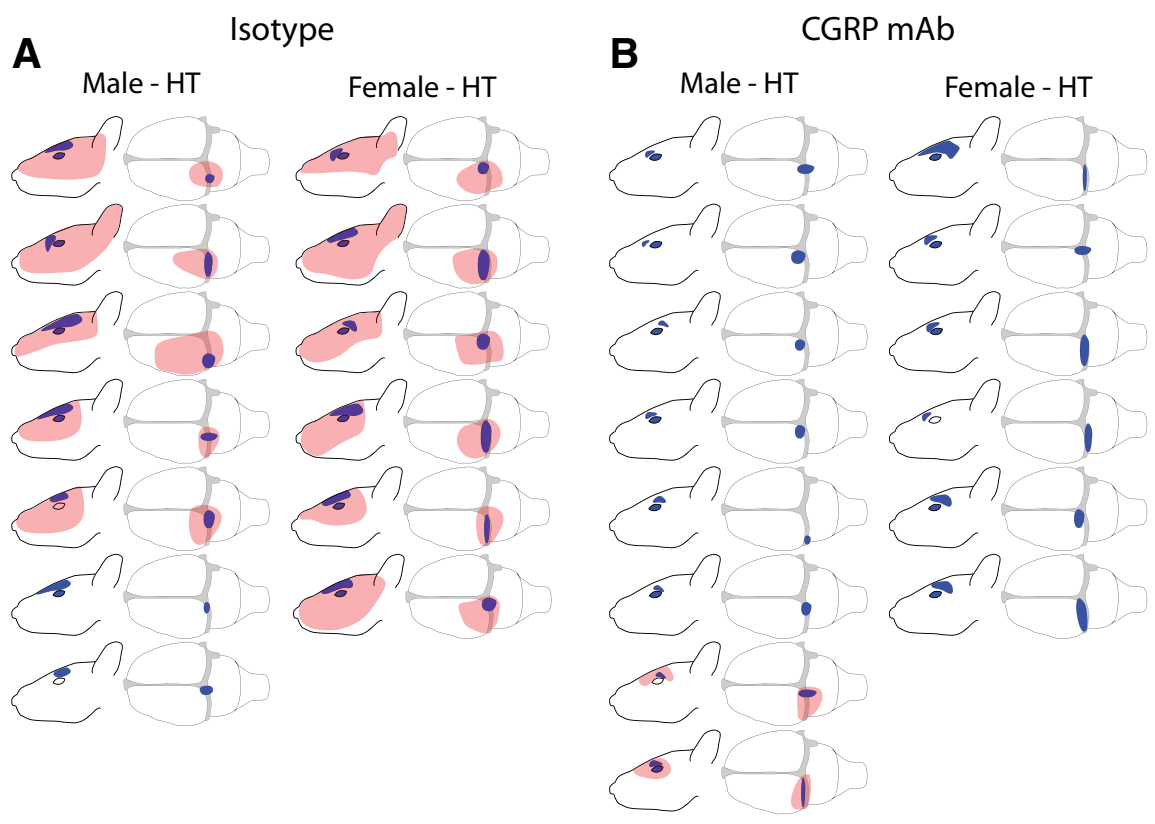

Figure 7. Expansion of dural and cutaneous receptive fields after occurrence of CSD in male and female rats. Blue and pink colors illustrate dural and cutaneous receptive fields before and $2 \mathrm{~h}$ after $C S D$ induction in isotype-conAb- $(\boldsymbol{A})$ and $C G R P-m A b(B)$-treated rats. Note that CGRP-mAb reduced the incidence of receptive field expansion.
$\operatorname{CSD}(p=0.027)$, whereas the mean firing rate of the 5 WDR neurons remained unchanged ( $2.6 \pm 1.2$ spikes/s before CSD vs $2.2 \pm 0.9$ after CSD, $p=0.73$ ) (Fig. 6C). In contrast, in the CGRP-mAb-treated rats, the response magnitude of the $6 \mathrm{HT}$ neurons remained unchanged $2 \mathrm{~h}$ after induction of CSD and $6 \mathrm{~h}$ after CGRPmAb administration $(3.3 \pm 1.7$ spikes $/ \mathrm{s}$ before CSD vs $5.0 \pm 3.4$ after CSD, $p=$ 0.45 ; Fig. $6 F$ ). As in the male, the expected CSD-induced activation of the HT neurons was prevented by the CGRP-mAb treatment.

To further examine CGRP-mAb effects on the activation of WDR and HT neurons by CSD, we also performed a case-by-case analysis. Of all CGRP-mAband isotype-conAb-treated WDR neurons, $5 / 13$ and $4 / 10$, respectively, were activated by CSD, a mere $2 \%$ difference. In contrast, of all CGRP-mAb and isotype-conAb-treated HT neurons, 2/14 and $13 / 13$, respectively, were activated by CSD, an $86 \%$ difference.

\section{Sensitivity of naive central trigeminovascular neurons to mechanical stimulation of the periorbital skin and the cornea Intravenous administration of the CGRP-mAb (Fig. 4A-D) or the isotype-conAb (Fig. 4E-H) did not alter the responses of HT or WDR neurons to innocuous (brush, pressure) or noxious (pinch) mechanical stimulation of the skin or the cornea (Fig. $5 A-F)$ in male or female rats.}

\section{Cortical spreading depression}

Effects of CGRP-mAb $(n=27)$ or isotype-conAb $(n=23)$ on activation of central trigeminovascular neurons by CSD was tested in 50 neurons in which baseline firing rate (i.e., mean spikes/s before induction of CSD) was reliable and consistent over hours. At baseline (i.e., before CSD), the spontaneous firing rate of $\mathrm{HT}$ and WDR neurons did not differ between the male and the female rats $(p=0.14)$. For the HT neurons, mean spikes/s before induction of CSD was $1.2 \pm 0.6$ in the male versus $3.3 \pm$ 1.7 in the female $(p=0.29)$. For the WDR neurons, mean spikes/s before induction of CSD was $1.5 \pm 0.6$ in the male versus $3.5 \pm 2.2$ in the female $(p=0.37)$.

\section{CSD-induced activity in central trigeminovascular neurons}

In male rats, $2 \mathrm{~h}$ after induction of CSD and $6 \mathrm{~h}$ after isotypeconAb administration, the mean firing rate of the 7 HT neurons increased from $1.1 \pm 0.8$ spikes/s before CSD to $10.2 \pm 2.1$ after CSD $(p=0.019)$, whereas the mean firing rate of the $5 \mathrm{WDR}$ neurons did not increase $(0.5 \pm 0.3$ spikes/s before CSD versus $1.6 \pm 0.5$ after CSD; $p=0.14$ ) (Fig. $6 A, B$ ). In contrast, in the CGRP-mAb-treated rats, the response magnitude of the $8 \mathrm{HT}$ neurons remained unchanged $2 \mathrm{~h}$ after induction of CSD and $6 \mathrm{~h}$ after CGRP-mAb administration (1.2 \pm 0.6 spikes/s before CSD vs $1.9 \pm 1.5$ after $C S D, p=0.29$; Fig. $6 D, E)$. In other words, the expected CSD-induced activation of the HT neurons was prevented by the CGRP-mAb treatment.

In female rats, $2 \mathrm{~h}$ after induction of CSD and $6 \mathrm{~h}$ after isotypeconAb administration, the mean firing rate of the 6 HT neurons increased from $1.9 \pm 1.0$ spikes/s before CSD to $10.0 \pm 4.5$ after
CSD-induced sensitization

Regardless of activation by CSD, 11/13 HT and none of the WDR neurons fulfilled our criteria for the development of sensitization (defined in the data analysis section). Therefore, CGRP-mAb ability to interfere with the development of sensitization after CSD is presented for HT but not WDR neurons.

Expansion of dural receptive fields and enhanced responses to mechanical stimulation of the dura after CSD

In the isotype-conAb-treated group, dural receptive fields expanded in 5/7 HT neurons in males and 6/6 HT neurons in females (Fig. 7A). Two hours after induction of CSD (6 h after isotype-conAb administration), neuronal responses to dural indentation with VFH increased in all 7 HT neurons in the males (12.8 \pm 3.9 spikes/s before CSD vs $22.0 \pm 3.7$ after CSD; $p=$ $0.026)$ and all 6 HT neurons in the females $(8.5 \pm 1.7$ before CSD vs $21.6 \pm 5.1$ after CSD, $p=0.047$ ) (Fig. $8 A-C$ ).

In contrast, in the CGRP-mAb-treated group, expansion of dural receptive fields, which was smaller when it occurred, was recorded in only $2 / 8 \mathrm{HT}$ neurons in the male and $0 / 6$ in the female (Fig. 7B). Two hours after induction of CSD (6 h after CGRP$\mathrm{mAb}$ administration), neuronal responses to dural indentation with VFH remained unchanged in all HT neurons in both the males $(1.8 \pm 0.6$ before CSD vs $1.9 \pm 1.5$ after CSD, $p=0.83)$ and the females $(10.5 \pm 1.6$ before CSD vs $8.1 \pm 6.4$ after CSD, $p=0.72$; Fig. $8 D-F)$, which is indicative of prevention of sensitization.

\section{Expansion of cutaneous receptive fields and enhanced} responses to mechanical stimulation of the periorbital skin after CSD (i.e., central sensitization)

In the isotype-conAb-treated group, facial receptive fields expanded in 5/7 HT neurons in males and 6/6 HT neurons in females (Fig. 7A). Two hours after induction of CSD (6 h after isotype-con $\mathrm{Ab}$ administration), responses to brush and pressure increased significantly in all 13 HT neurons (7 in males, 6 in females) (Fig. 9A-C). In males, responses to brush and pressure 


\section{Isotype}
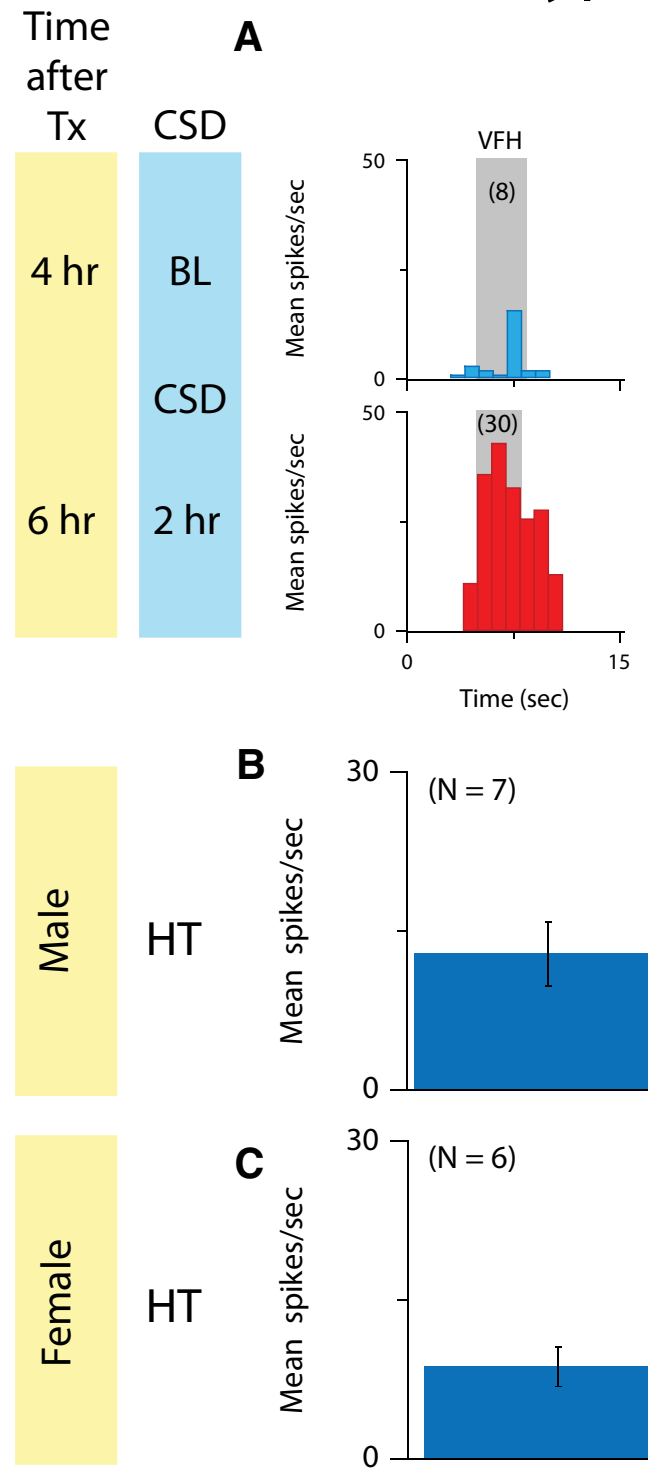

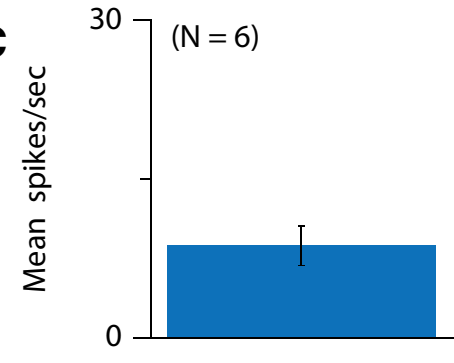

Baseline
B

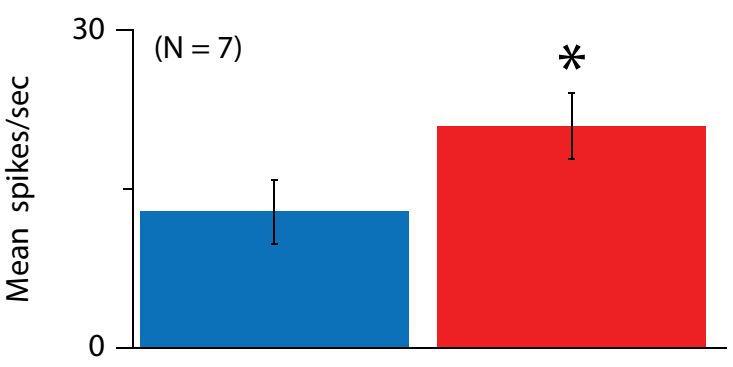

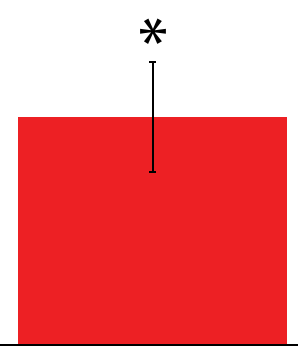

$2 \mathrm{~h}$

\section{CGRP mAb}

D

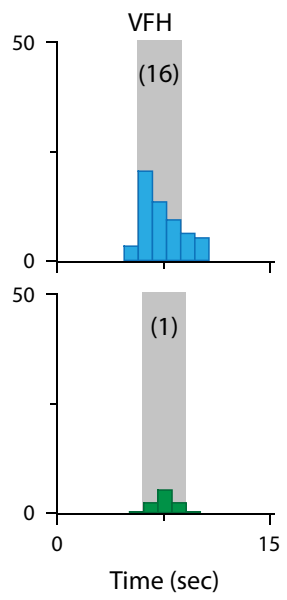

E 30

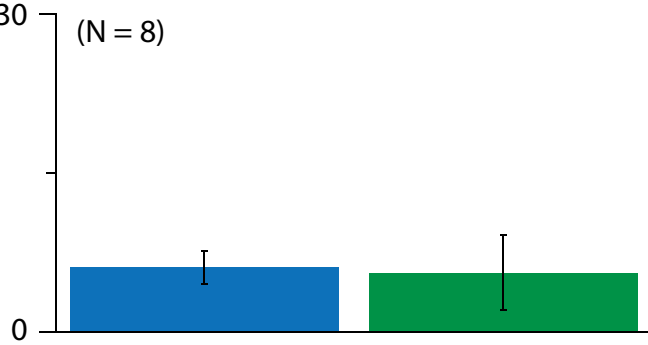

F

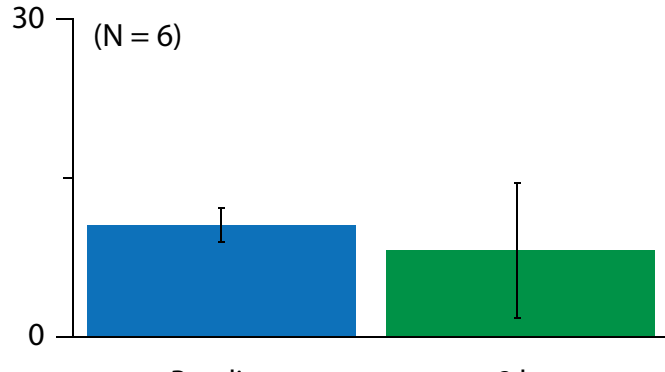

Baseline

$2 \mathrm{~h}$

Figure 8. Enhanced responses to mechanical stimulation of the dura after CSD are prevented by CGRP-mAb. $A, D$, Responses to indentation of the dura before CSD induction (BL) and $2 \mathrm{~h}$ after CSD in $2 \mathrm{HT}$ neurons that received treatment with isotype-conAb $(\boldsymbol{A})$ or $C G R P-m A b(D) 4 \mathrm{~h}$ before CSD induction. Numbers in parentheses show the mean discharge rate during each stimulus. Bin width $=$ 1 S. $\boldsymbol{B}, \boldsymbol{C}, \boldsymbol{E}, \boldsymbol{F}$, Mean ( \pm SE) discharge in response to dural indentation before CSD induction (baseline) and $2 \mathrm{~h}$ after CSD in neurons that received treatment with isotype-conAb ( $\boldsymbol{B}, \boldsymbol{C}$ ) or $(G R P$-mAb $(\boldsymbol{E}, \boldsymbol{F})$. Neurons recorded in males are shown in $\boldsymbol{B}$ and $\boldsymbol{E}$; neurons recorded in females are shown in $\boldsymbol{C}$ and $\boldsymbol{F} .{ }^{*} p<0.05$ compared with baseline. Numbers in parentheses in $\boldsymbol{B}, \boldsymbol{C}, \boldsymbol{E}$, and $\boldsymbol{F}$ depict the number of neurons in each group. Note that CGRP-mAb prevented the development of intracranial mechanical hypersensitivity in HT neurons in both sexes.

increased from 0.0 to $18.2 \pm 9.1$ spikes/s $(p=0.046)$ and from $16.6 \pm 4.2$ to $35.8 \pm 9.1$ spikes/s $(p=0.045)$, respectively (Fig. $9 B)$. In females, responses to brush and pressure increased from 0.0 to $8 \pm 6.5$ spikes/s $(p=0.027)$ and from $9.3 \pm 2.7$ to $31.8 \pm$ 13.6 spikes/s $(p=0.016)$, respectively (Fig. $9 C)$. In contrast, responses to pinch increased significantly in all HT neurons in females (19.3 \pm 5.0 spikes/s before CSD vs $45.8 \pm 12.4$ spikes/s after CSD, $n=6, p=0.027)$, but not in the males $(33.8 \pm 7.1$ spikes/s before CSD vs $52.4 \pm 10.3$ spikes/s after CSD, $n=6, p=$ 0.068) (Fig. 9B,C).

In the CGRP-mAb-treated rats, facial receptive fields expanded in only $2 / 8 \mathrm{HT}$ neurons in males and $0 / 6$ HT neurons in females. Two hours after induction of CSD ( $6 \mathrm{~h}$ after CGRP-mAb administration), neuronal responses to brush $(p=0.35)$, pres- sure $(p=0.63)$, and pinch $(p=0.78)$ remained unchanged in all HT neurons in both males and females (Fig. $9 D-F$ ), suggesting that the CGRP-mAb prevented induction of sensitization.

\section{Enhanced responses to corneal stimulation after CSD}

In the isotype-conAb-treated rats, responses to corneal stimulation after CSD increased significantly in female $(7.6 \pm 1.9$ spikes/s before CSD vs $21.0 \pm 6.4$ spikes/s after CSD, $n=6, p=$ $0.044)$, but not in male ( $11.0 \pm 2.6$ spikes/s before CSD vs $21.6 \pm$ 8.7 spikes/s after CSD, $n=7, p=0.19$ ) HT neurons (Fig. 10A-C).

In the CGRP-mAb-treated female rats, response to brushing the cornea remained unchanged in the 6 HT neurons $(p=0.51)$, suggesting prevention of sensitization, and, as expected, it also remained unchanged in the 8 HT neurons in the males $(10.8 \pm$ 


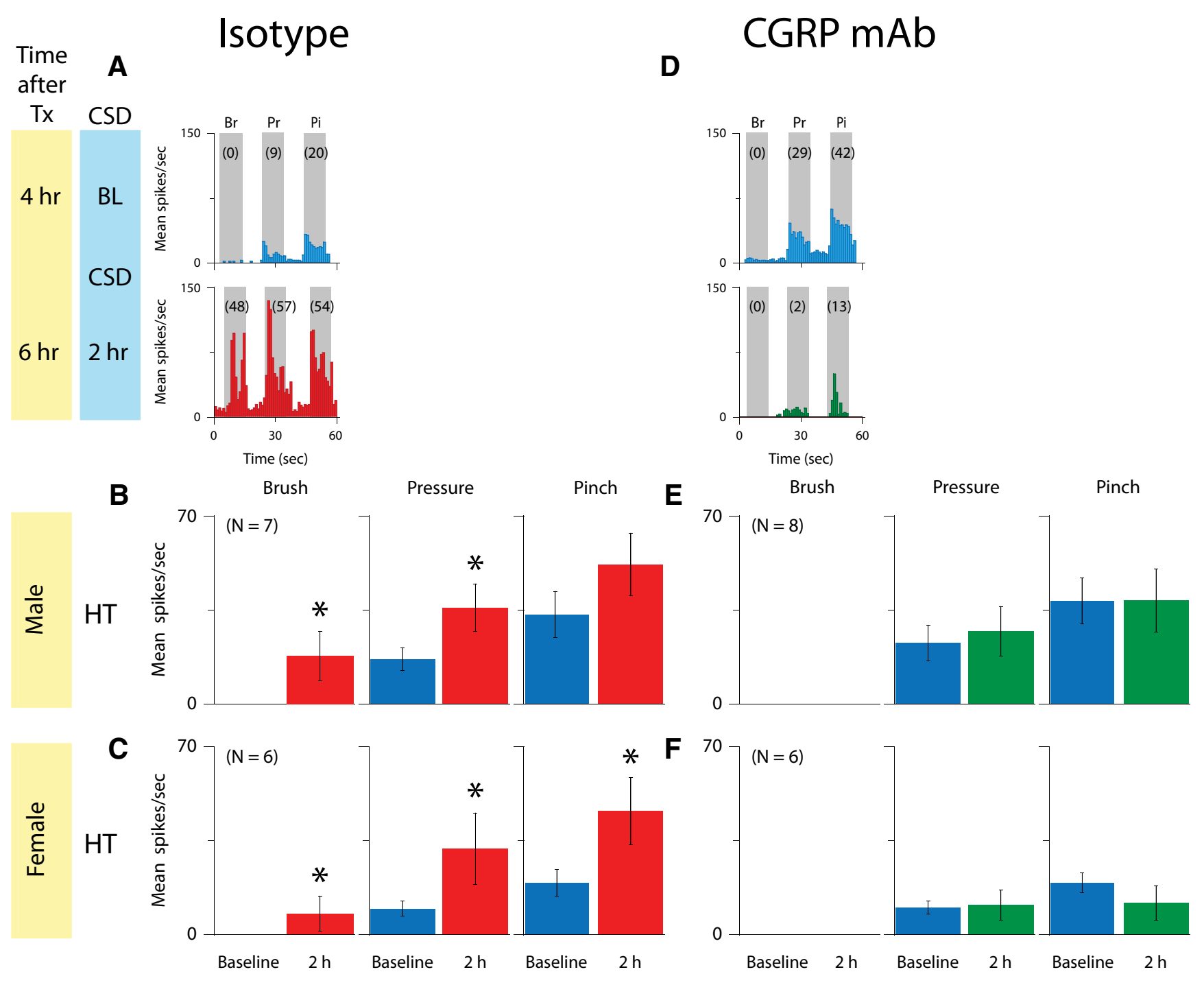

Figure 9. Enhanced responses to cutaneous stimulation after CSD are prevented by CGRP-mAb.A, D, Responses to mechanical stimulation of the cutaneous receptive fields with brush, pressure, and pinch before $C S D$ induction (baseline, $\mathrm{BL}$ ) and $2 \mathrm{~h}$ after $\mathrm{CSD}$ for $2 \mathrm{HT}$ neurons that received isotype-conAb $(\boldsymbol{A})$ or CGRP-mAb $(\boldsymbol{D}) 4 \mathrm{~h}$ before CSD induction. Numbers in parentheses show the mean discharge rate during each stimulus. Bin width $=1 \mathrm{~S}, \boldsymbol{B}, \boldsymbol{C}, \boldsymbol{E}, \boldsymbol{F}, \mathrm{Mean}$ ( $\pm \mathrm{SE}$ ) discharge in response to cutaneous stimulation before (baseline) and $2 \mathrm{~h}$ after $(S D$ induction in $\mathrm{HT}$ neurons that received treatment with isotype-conAb or CGRP-mAb $4 \mathrm{~h}$ before CSD induction. Neurons recorded in males are shown in $\boldsymbol{B}$ and $\boldsymbol{E}$; neurons recorded in females are shown in $\boldsymbol{C}$ and $\boldsymbol{F}$. ${ }^{*} p<0.05$ compared with baseline. Note that CGRP-mAb prevented the development of cutaneous mechanical hypersensitivy in $\mathrm{HT}$ neurons in both sexes.

3.3 spikes/s before CSDS vs $9.4 \pm 1.8$ spikes/s after CSD, $p=0.60)$ (Fig. 10D-F).

\section{Discussion}

This study demonstrates that the humanized CGRP-mAb fremanezumab inhibits activation and sensitization of HT but not WDR trigeminovascular neurons (Fig. 11). In males, the CGRP$\mathrm{mAb}$ inhibited the spontaneous activity of naive HT neurons and their responses to stimulation of the intracranial dura but not facial skin or cornea, whereas, in females, it only inhibited their responses to stimulation of the intracranial dura. When given sufficient time, however, the CGRP-mAb prevented in both sexes the activation and consequential sensitization of the HT neurons by CSD, but not the partial activation of WDR neurons. Mechanistically, these findings suggest that HT neurons play a critical role (not recognized before) in the initiation of the perception of headache and the development of allodynia and central sensitization. Clinically, the present findings may help to explain the therapeutic effectiveness of CGRP-mAb in preventing headaches of intracranial origin such as migraine and why this therapeutic approach may not be effective for every migraine patient. Although our data show little effect on the processing of nociceptive signals that originate extracranially (skin, cornea), it may be interesting to determine whether CGRP-mAb can prevent headaches/migraine of extracranial origin.

This is the first study to our knowledge to test the effects of CGRP-mAb on the responsiveness of different classes of central trigeminovascular neurons. Previously, Storer et al. (2004) showed that the CGRP-R antagonist BIBN4096BS inhibits naive central trigeminovascular neuron responses to electrical stimulation of the superior sagittal sinus and microiontophoretic administration of L-glutamate.

\section{Fremanezumab effects on HT versus WDR}

When given intravenously, CGRP-mAb reduced baseline spontaneous activity in HT but not WDR neurons. Considering current and previous evidence that WDR trigeminovascular neurons are activated by a variety of dural stimulation used to study the 


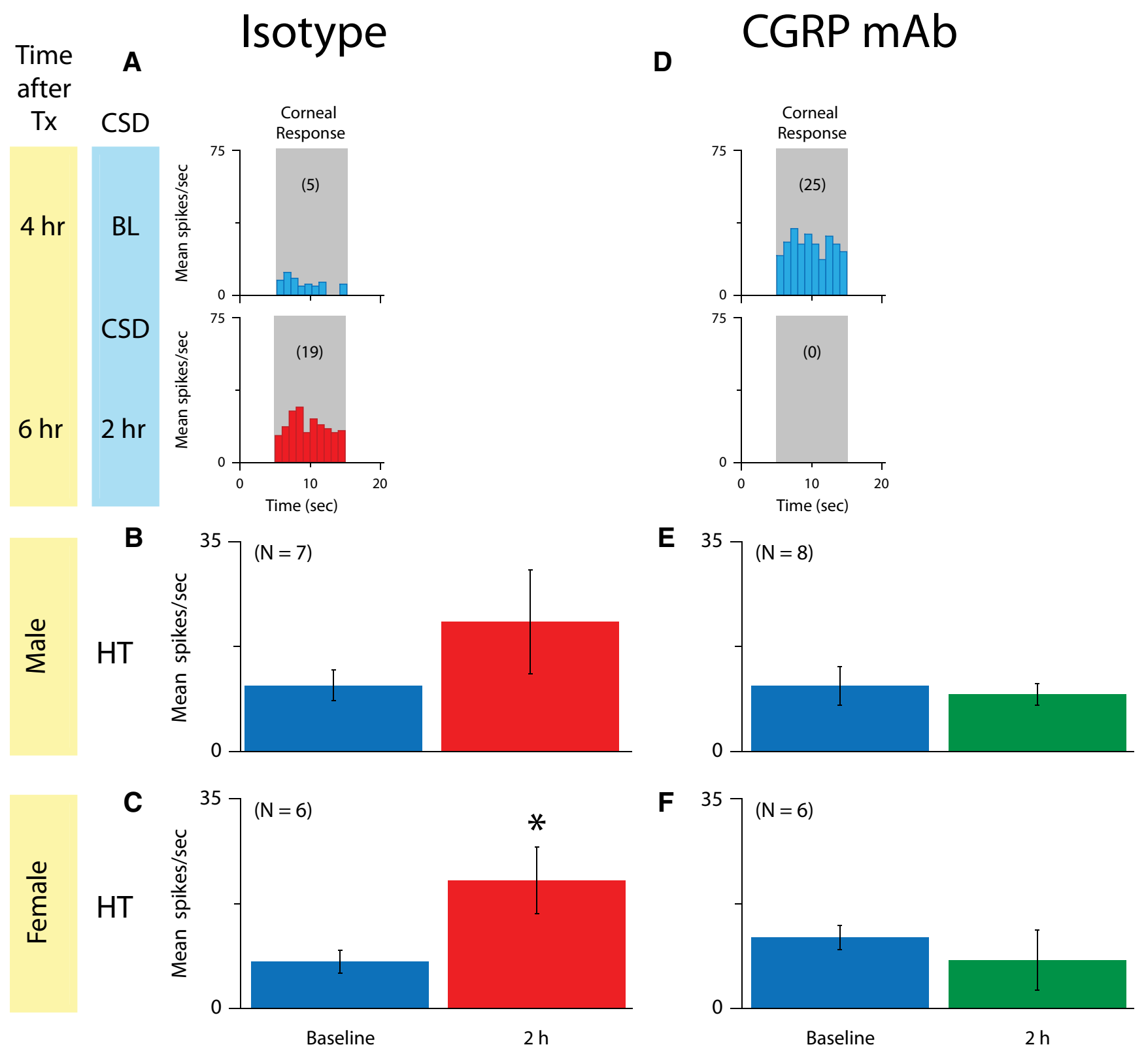

Figure 10. Enhanced responses to mechanical stimulation of the cornea after CSD are prevented by CGRP-mAb (female only). $\boldsymbol{A}, \boldsymbol{D}$, Responses to corneal stimulation (gentle brush) before CSD induction (BL) and $2 \mathrm{~h}$ after CSD in $2 \mathrm{HT}$ neurons that received treatment with isotype-conAb (A) or CGRP-mAb (D) $4 \mathrm{~h}$ before CSD induction. Bin width $=1 \mathrm{~s} . \boldsymbol{B}, \boldsymbol{C}, E, F$, Mean $( \pm S E)$ discharge in response to corneal stimulation before $C S D$ induction (baseline) and $2 \mathrm{~h}$ after $C S D$ in neurons that received treatment with isotype-conAb $(\boldsymbol{B}, \boldsymbol{C})$ or $(G R P-m A b(E, F) 4 \mathrm{~h}$ before $C S D$ induction. Neurons recorded in males are shown in $\boldsymbol{B}$ and $\boldsymbol{E}$; neurons recorded in females are shown in $\boldsymbol{C}$ and $\boldsymbol{F}$. ${ }^{*} p<0.05$ compared with baseline. Note that CGRP-mAb prevented the development of corneal hypersensitivy in $\mathrm{HT}$ neurons in female but not male rats.

pathophysiology of migraine (Davis and Dostrovsky, 1988; Burstein et al., 1998; Storer et al., 2004; Zhang et al., 2011), it is reasonable to conclude that activation of WDR alone is insufficient to induce the headache perception in episodic migraine patients whose headaches are completely or nearly completely prevented by CGRP-mAb therapy (Bigal et al., 2015a). Conversely, it is also reasonable to speculate that activation of WDR trigeminovascular neurons alone may be sufficient to induce the headache perception in those episodic migraine patients who do not benefit from CGRP-mAb therapy because the headache could be unaffected by elimination of the signals sent to the thalamus from HT trigeminovascular neurons.

Outside of migraine and the trigeminovascular system, HT and WDR neurons have also been thought to play different roles in the processing of noxious stimuli and the perception of pain (Craig, 2002, 2003a, 2003b). Although most HT neurons exhibit small receptive fields and respond exclusively to noxious mechanical stimuli, most WDR neurons exhibit large receptive fields and respond to both mechanical and thermal noxious stimuli (Price et al., 1976; Price et al., 1978; Hoffman et al., 1981; Dubner and Bennett, 1983; Bushnell et al., 1984; Surmeier et al., 1986; Ferrington et al., 1987; Dubner et al., 1989; Maixner et al., 1989; Laird and Cervero, 1991). Based on these differences, it is generally believed that HT neurons make a greater contribution to the spatial encoding (size, location) of pain and a lesser contribution to the encoding of pain modalities, whereas WDR neurons make a greater contribution to the radiating qualities of the pain. It is also reasonable to hypothesize that those patients 
Naïve state

\begin{tabular}{|c|c|c|c|c|}
\hline & \multicolumn{2}{|c|}{ Male } & \multicolumn{2}{|c|}{ Female } \\
\hline \multicolumn{5}{|c|}{ Spontaneous Activity } \\
\hline & $\mathrm{HT}$ & WDR & $\mathrm{HT}$ & WDR \\
\hline CGRP-mAb & Inhibition & No inhibition & No inhibition & No inhibition \\
\hline Isotype & No inhibition & No inhibition & No inhibition & No inhibition \\
\hline \multicolumn{5}{|c|}{ Von Frey Hair (Dura) } \\
\hline & HT & WDR & HT & WDR \\
\hline CGRP-mAb & Inhibition & No inhibition & Inhibition & No inhibition \\
\hline Isotype & No inhibition & No inhibition & No inhibition & No inhibition \\
\hline \multicolumn{5}{|l|}{ Brush } \\
\hline & HT & WDR & HT & WDR \\
\hline CGRP-mAb & No inhibition & No inhibition & No inhibition & No inhibition \\
\hline Isotype & No inhibition & No inhibition & No inhibition & No inhibition \\
\hline \multicolumn{5}{|l|}{ Pressure } \\
\hline & $\mathrm{HT}$ & WDR & $\mathrm{HT}$ & WDR \\
\hline CGRP-mAb & No inhibition & No inhibition & No inhibition & No inhibition \\
\hline Isotype & No inhibition & No inhibition & No inhibition & No inhibition \\
\hline \multicolumn{5}{|l|}{ Pinch } \\
\hline & $\mathrm{HT}$ & WDR & HT & WDR \\
\hline CGRP-mAb & No inhibition & No inhibition & No inhibition & No inhibition \\
\hline Isotype & No inhibition & No inhibition & No inhibition & No inhibition \\
\hline \multicolumn{5}{|l|}{ Cornea } \\
\hline & HT & WDR & HT & WDR \\
\hline CGRP-mAb & No inhibition & No inhibition & No inhibition & No inhibition \\
\hline Isotype & No inhibition & No inhibition & No inhibition & No inhibition \\
\hline
\end{tabular}

Post-CSD state

\begin{tabular}{l}
\hline \multicolumn{2}{|c|}{ Male } \\
\begin{tabular}{|c|c|}
\hline HT & WDR \\
\hline Prevention & No prevention \\
\hline Activation/sensitization & Partial activation \\
\hline \multicolumn{2}{|c|}{} \\
\hline HT & WDR \\
\hline Prevention & No sensitization \\
\hline Sensitization & No sensitization \\
\hline
\end{tabular}
\end{tabular}

\begin{tabular}{|c|c|}
\hline \multicolumn{2}{|c|}{ Female } \\
\hline $\mathrm{HT}$ & WDR \\
\hline Prevention & No prevention \\
\hline Activation/sensitization & Partial activation \\
\hline HT & WDR \\
\hline Prevention & No sensitization \\
\hline Sensitization & No sensitization \\
\hline HT & WDR \\
\hline Prevention & No sensitization \\
\hline Sensitization & No sensitization \\
\hline HT & WDR \\
\hline Prevention & No sensitization \\
\hline Sensitization & No sensitization \\
\hline HT & WDR \\
\hline Prevention & No sensitization \\
\hline Sensitization & No sensitization \\
\hline HT & WDR \\
\hline Prevention & No sensitization \\
\hline Sensitization & No sensitization \\
\hline
\end{tabular}

Figure 11. Summary of effects of Fremanezumab (GRP-mAb) vs isotype on HT and WDR neurons in the naïve and post-CSD state. Naïve state. CGRP-mAb, but not isotype, inhibits baseline (naïve state) spontaneous activity and dural mechanosensitivity in males, and dural mechanosensitivity in females, of HT but not WDR neurons. Post-CSD state. CSD produces activation/sensitization (increased spontaneous activity) and sensitization of responses to dural mechanical stimulation and facial brush and pressure in male HT neurons, and, in addition to these effects, also produces sensitization to facial pinch and corneal mechanical stimulation in female HT neurons. CSD produces partial activation in male and female WDR neurons. CGRP-mAb, but not isotype, prevents the sensitizing effects of CSD in HT neurons, but not in WDR neurons.

unresponsive to fremanezumab are the ones whose headaches affect large areas of the head (i.e., frontal, temporal, occipital, bilateral), whereas the ones whose headaches are well localized to small and distinct areas will be among the responders.

\section{Specificity to headache}

Fremanezumab reduced responsiveness to mechanical stimulation of the dura (both in males and females), but not to innocuous or noxious stimulation of the skin or cornea. This finding, together with the fact that the CGRP-mAb also prevented the activation of HT trigeminovascular neurons by CSD, provides a scientific basis for fremanezumab's effectiveness in preventing headaches of intracranial origin. Conversely, lack of effects on modulating the processing of sensory and nociceptive signals that arise in the facial skin and cornea predicts that this class of drugs will have little therapeutic effect on treating prolonged trigeminal pain conditions such as dry eye and herpes-induced trigeminal neuralgia. Given that fremanezumab inhibited activation of central trigeminovascular neurons from the dura (mechanical, CSD), but not skin or cornea, and that the size of this molecule is too large to penetrate the blood-brain barrier readily, it is reasonable to suggest that the inhibitory effects described above were secondary to (primary) inhibition of responses to dural indentation and CSD in peripheral trigeminovascular neurons.

Given the wide distribution throughout the body of CGRP fibers (Kruger et al., 1988; Kruger et al., 1989; Silverman and Kruger, 1989) and their presence in multiple spinal cord segments (Hansen et al., 2016; Nees et al., 2016) and in multiple sensory dorsal root ganglia (Edvinsson et al., 1998; Edvinsson et al., 2001; Cho et al., 2015; Kestell et al., 2015; Spencer et al., 2016), it is surprising that the CGRP-mAb had little or no effect on the responses of the central neurons to noxious stimulation of the skin and cornea. If one accepts the notion that the CGRP-mAb acts mainly in the periphery, it is also reasonable to propose that peripheral aspects of the sensory innervation of the meninges and the way that this innervation affects sensory transmission in the dorsal horn differ from those involved in the generation of cutaneous, corneal, or other (somatic) pains. Studies on fremanezumab's effects in animal models of other pain conditions should allow us to interpret more accurately the difference between CGRP-mAb effects in the dura versus extracranial tissues not believed to have a distinct initiating role in migraine.

\section{Inhibition of CSD-induced activation and sensitization}

To the best of our knowledge, this is the first demonstration of sensitization of central trigeminovascular neurons by CSD. This sensitization, which we observed in HT but not WDR neurons in both males and females, was prevented by the CGRP-mAb administration. These novel findings raise the possibility that cutaneous allodynia in attacks preceded by aura (Burstein et al., 2000) is mediated by HT neurons that are unresponsive to innocuous mechanical stimulation of the skin at baseline (interictally in patients and before induction of CSD in animals), but becomes mechanically responsive to brush after the CSD. According to this scenario, one would predict that, among migraine aura patients, responders to the prophylactic treatment of CGRP-mAb would show no signs of cutaneous allodynia, a potential biomarker of treatment success and a readily testable hypothesis.

\section{Male versus female}

This is also the first study to test CGRP-mAb effects in both male and female rats. Although our overall analysis-by-sex (which we cannot compare to any previous study) suggests that the therapeutic benefit of this class of drugs should be similar in male and female migraineurs, it also shows that, in the naive state, CGRP$\mathrm{mAb}$ reduces the spontaneous activity in male but not female HT 
neurons and that, after induction of sensitization by CSD, only HT neurons recorded in females exhibited signs of sensitization to noxious stimulation of the skin and cornea. Given that migraine is more common in women than men, it is tempting to interpret the differences as suggesting that hyperalgesia (rather than allodynia) is more likely to develop in women than in men during migraine with aura and that attempts to reduce neuronal excitability by CGRP-mAb in the interictal state (i.e., as a preventative) may also be more challenging in women than in men. Mechanistically, the three observed differences could be attributed to greater excitability of female HT neurons either due to these neurons' internal properties or to differences in the strength of inputs that they receive from peripheral nociceptors. Whereas no data exist to support the first option, it is possible that differences in the activation of dural immune cells and inflammatory molecules in females compared with males (Mcllvried et al., 2015) can support the second option. Regarding fremanezumab's ability to reduce spontaneous activity in male but not female rats, one may take into consideration data showing that female rats express fewer CGRP receptors in the trigeminal ganglion and spinal trigeminal nucleus and higher levels of CGRP-encoding mRNA in the dorsal horn (Stucky et al., 2011).

Finally, whereas most HT neurons were inhibited by the fremanezumab within 3-4 h, a few were inhibited within $1-2 \mathrm{~h}$. These relatively short times (hours rather than days), however, were achieved using intravenous rather than the subcutaneous administration mode reported in the clinical trials with fremanezumab (Bigal et al., 2015a; Bigal et al., 2015b). To date, no information is available to allow one to speculate on the mechanisms/reasons for the delayed (hours rather than seconds) inhibition of the neurons by the intravenous administration of the CGRP-mAb. In the absence of an immediate effect, it may be reasonable to speculate that CGRP-mAb inhibits the peripheral trigeminovascular neurons indirectly by altering meningeal immune and or vascular functions.

We must state the caveat that the occurrence of CSD was verified by recording an ECG just anterior to the visual cortex using a glass micropipette. Therefore, the possibility that CSD was unintentionally triggered by the insertion of this micropipette was accounted for and ruled out by a continuous ECG recording. The small size of the tip $(7 \mu \mathrm{m})$ and the short insertion distance $(<100 \mu \mathrm{m})$ may account for the lack of CSD. Furthermore, the ECG recording electrode was placed in the cortex at least $2 \mathrm{~h}$ before beginning of neuronal recording and $6 \mathrm{~h}$ before final reading of neuronal activity.

\section{References}

Bellamy JL, Cady RK, Durham PL (2006b) Salivary levels of CGRP and VIP in rhinosinusitis and migraine patients. Headache 46:24-33. CrossRef Medline

Bellamy J, Bowen EJ, Russo AF, Durham PL (2006a) Nitric oxide regulation of calcitonin gene-related peptide gene expression in rat trigeminal ganglia neurons. Eur J Neurosci 23:2057-2066. CrossRef Medline

Bigal ME, Dodick DW, Rapoport AM, Silberstein SD, Ma Y, Yang R, Loupe PS, Burstein R, Newman LC, Lipton RB (2015a) Safety, tolerability, and efficacy of TEV-48125 for preventive treatment of high-frequency episodic migraine: a multicentre, randomised, double-blind, placebo-controlled, phase 2b study. Lancet Neurol 14:1081-1090. CrossRef Medline

Bigal ME, Edvinsson L, Rapoport AM, Lipton RB, Spierings EL, Diener HC, Burstein R, Loupe PS, Ma Y, Yang R, Silberstein SD (2015b) Safety, tolerability, and efficacy of TEV-48125 for preventive treatment of chronic migraine: a multicentre, randomised, double-blind, placebo-controlled, phase 2b study. Lancet Neurol 14:1091-1100. CrossRef Medline

Burstein R, Yamamura H, Malick A, Strassman AM (1998) Chemical stimulation of the intracranial dura induces enhanced responses to facial stim- ulation in brain stem trigeminal neurons. J Neurophysiol 79:964-982. Medline

Burstein R, Yarnitsky D, Goor-Aryeh I, Ransil BJ, Bajwa ZH (2000) An association between migraine and cutaneous allodynia. Ann Neurol 47: 614-624. Medline

Burstein R, Noseda R, Borsook D (2015) Migraine: multiple processes, complex pathophysiology. J Neurosci 35:6619-6629. CrossRef Medline

Bushnell MC, Duncan GH, Dubner R, He LF (1984) Activity of trigeminothalamic neurons in medullary dorsal horn of awake monkeys trained in a thermal discrimination task. J Neurophysiol 52:170-187. Medline

Buzzi MG, Carter WB, Shimizu T, Heath H 3rd, Moskowitz MA (1991) Dihydroergotamine and sumatriptan attenuate levels of CGRP in plasma in rat superior sagittal sinus during electrical stimulation of the trigeminal ganglion. Neuropharmacology 30:1193-1200. CrossRef Medline

Cady RK, Vause CV, Ho TW, Bigal ME, Durham PL (2009) Elevated saliva calcitonin gene-related peptide levels during acute migraine predict therapeutic response to rizatriptan. Headache 49:1258-1266. CrossRef Medline

Cho HK, Ahn SH, Kim SY, Choi MJ, Hwang SJ, Cho YW (2015) Changes in the expressions of Ibal and calcitonin gene-related peptide in adjacent lumbar spinal segments after lumbar disc herniation in a rat model. J Korean Med Sci 30:1902-1910. CrossRef Medline

Craig AD (2002) How do you feel? Interoception: the sense of the physiological condition of the body. Nat Rev Neurosci 3:655-666. CrossRef Medline

Craig AD (2003a) Pain mechanisms: labeled lines versus convergence in central processing. Annu Rev Neurosci 26:1-30. CrossRef Medline

Craig AD (2003b) A new view of pain as a homeostatic emotion. Trends Neurosci 26:303-307. CrossRef Medline

Dado RJ, Katter JT, Giesler GJ Jr (1994) Spinothalamic and spinohypothalamic tract neurons in the cervical enlargement of rats. II. Responses to innocuous and noxious mechanical and thermal stimuli. J Neurophysiol 71:981-1002. Medline

Davis KD, Dostrovsky JO (1988) Responses of feline trigeminal spinal tract nucleus neurons to stimulation of the middle meningeal artery and sagittal sinus. J Neurophysiol 59:648-666. Medline

Dodick DW, Goadsby PJ, Spierings EL, Scherer JC, Sweeney SP, Grayzel DS (2014a) Safety and efficacy of LY2951742, a monoclonal antibody to calcitonin gene-related peptide, for the prevention of migraine: a phase 2 , randomised, double-blind, placebo-controlled study. Lancet Neurol 13:885892. CrossRef Medline

Dodick DW, Goadsby PJ, Silberstein SD, Lipton RB, Olesen J, Ashina M, Wilks K, Kudrow D, Kroll R, Kohrman B, Bargar R, Hirman J, Smith J; ALD403 study investigators. (2014b) Safety and efficacy of ALD403, an antibody to calcitonin gene-related peptide, for the prevention of frequent episodic migraine: a randomised, double-blind, placebo-controlled, exploratory phase 2 trial. Lancet Neurol 13:1100-1107. CrossRef Medline

Dubner R, Bennett GJ (1983) Spinal and trigeminal mechanisms of nociception. Annu Rev Neurosci 6:381-418. CrossRef Medline

Dubner R, Kenshalo DR Jr, Maixner W, Bushnell MC, Oliveras JL (1989) The correlation of monkey medullary dorsal horn neuronal activity and the perceived intensity of noxious heat stimuli. J Neurophysiol 62:450457. Medline

Durham PL, Russo AF (1998) Serotonergic repression of mitogen-activated protein kinase control of the calcitonin gene-related peptide enhancer. Mol Endocrinol 12:1002-1009. CrossRef Medline

Durham PL, Russo AF (1999) Regulation of calcitonin gene-related peptide secretion by a serotonergic antimigraine drug. J Neurosci 19:3423-3429. Medline

Durham PL, Russo AF (2003) Stimulation of the calcitonin gene-related peptide enhancer by mitogen- activated protein kinases and repression by an antimigraine drug in trigeminal ganglia neurons. J Neurosci 23:807815. Medline

Durham PL, Sharma RV, Russo AF (1997) Repression of the calcitonin gene-related peptide promoter by $5-\mathrm{HT} 1$ receptor activation. J Neurosci 17:9545-9553. Medline

Durham PL, Dong PX, Belasco KT, Kasperski J, Gierasch WW, Edvinsson L, Heistad DD, Faraci FM, Russo AF (2004) Neuronal expression and regulation of CGRP promoter activity following viral gene transfer into cultured trigeminal ganglia neurons. Brain Res 997:103-110. CrossRef Medline

Edvinsson L, Mulder H, Goadsby PJ, Uddman R (1998) Calcitonin generelated peptide and nitric oxide in the trigeminal ganglion: cerebral vaso- 
dilatation from trigeminal nerve stimulation involves mainly calcitonin gene-related peptide. J Auton Nerv Syst 70:15-22. CrossRef Medline

Edvinsson L, Elsås T, Suzuki N, Shimizu T, Lee TJ (2001) Origin and Colocalization of nitric oxide synthase, CGRP, PACAP, and VIP in the cerebral circulation of the rat. Microsc Res Tech 53:221-228. CrossRef Medline

Eltorp CT, Jansen-Olesen I, Hansen AJ (2000) Release of calcitonin generelated peptide (CGRP) from guinea pig dura mater in vitro is inhibited by sumatriptan but unaffected by nitric oxide. Cephalalgia 20:838-844. CrossRef Medline

Ferrington DG, Sorkin LS, Willis WD Jr (1987) Responses of spinothalamic tract cells in the superficial dorsal horn of the primate lumbar spinal cord. J Physiol 388:681-703. CrossRef Medline

Goadsby PJ, Edvinsson L (1994) Joint 1994 Wolff Award Presentation. Peripheral and central trigeminovascular activation in cat is blocked by the serotonin (5HT)-1D receptor agonist 311C90. Headache 34:394-399. CrossRef Medline

Goadsby PJ, Edvinsson L, Ekman R (1990) Vasoactive peptide release in the extracerebral circulation of humans during migraine headache. Ann Neurol 28:183-187. CrossRef Medline

Hansen JM, Ashina M (2014) Calcitonin gene-related peptide and migraine with aura: a systematic review. Cephalalgia 34:695-707. CrossRef Medline

Hansen JM, Hauge AW, Olesen J, Ashina M (2010) Calcitonin gene-related peptide triggers migraine-like attacks in patients with migraine with aura. Cephalalgia 30:1179-1186. CrossRef Medline

Hansen RR, Vacca V, Pitcher T, Clark AK, Malcangio M (2016) Role of extracellular calcitonin gene-related peptide in spinal cord mechanisms of cancer-induced bone pain. Pain 157:666-676. CrossRef Medline

Hoffman DS, Dubner R, Hayes RL, Medlin TP (1981) Neuronal activity in medullary dorsal horn of awake monkeys trained in a thermal discrimination task. I. Responses to innocuous and noxious thermal stimuli. J Neurophysiol 46:409-427. Medline

Kaiser EA, Kuburas A, Recober A, Russo AF (2012) Modulation of CGRPinduced light aversion in wild-type mice by a 5-HT(1B/D) agonist. J Neurosci 32:15439-15449. CrossRef Medline

Karsan N, Goadsby PJ (2015) Calcitonin gene-related peptide and migraine. Curr Opin Neurol 28:250-254. CrossRef Medline

Keller JT, Marfurt CF (1991) Peptidergic and serotoninergic innervation of the rat dura mater. J Comp Neurol 309:515-534. CrossRef Medline

Kestell GR, Anderson RL, Clarke JN, Haberberger RV, Gibbins IL (2015) Primary afferent neurons containing calcitonin gene-related peptide but not substance $\mathrm{P}$ in forepaw skin, dorsal root ganglia, and spinal cord of mice. J Comp Neurol 523:2555-2569. CrossRef Medline

Kruger L, Sternini C, Brecha NC, Mantyh PW (1988) Distribution of calcitonin gene-related peptide immunoreactivity in relation to the rat central somatosensory projection. J Comp Neurol 273:149-162. CrossRef Medline

Kruger L, Silverman JD, Mantyh PW, Sternini C, Brecha NC (1989) Peripheral patterns of calcitonin-gene-related peptide general somatic sensory innervation: cutaneous and deep terminations. J Comp Neurol 280:291302. CrossRef Medline

Laird JM, Cervero F (1991) Signalling of a step-like intensity change of noxious mechanical stimuli by dorsal horn neurones in the rat spinal cord. J Physiol 434:561-575. CrossRef Medline

Lawson SN, Perry MJ, Prabhakar E, McCarthy PW (1993) Primary sensory neurones: neurofilament, neuropeptides, and conduction velocity. Brain Res Bull 30:239-243. CrossRef Medline

Lawson SN, McCarthy PW, Prabhakar E (1996) Electrophysiological properties of neurones with CGRP-like immunoreactivity in rat dorsal root ganglia. J Comp Neurol 365:355-366. Medline

Lawson SN, Crepps B, Perl ER (2002) Calcitonin gene-related peptide immunoreactivity and afferent receptive properties of dorsal root ganglion neurones in guinea-pigs. J Physiol 540:989-1002. Medline

Maixner W, Dubner R, Kenshalo DR Jr, Bushnell MC, Oliveras JL (1989) Responses of monkey medullary dorsal horn neurons during the detection of noxious heat stimuli. J Neurophysiol 62:437-449. Medline

McCarthy PW, Lawson SN (1990) Cell type and conduction velocity of rat primary sensory neurons with calcitonin gene-related peptide-like immunoreactivity. Neuroscience 34:623-632. CrossRef Medline

McIlvried LA, Borghesi LA, Gold MS (2015) Sex-, stress-, and sympathetic post-ganglionic neuron-dependent changes in the expression of pro- and anti-inflammatory mediators in rat dural immune cells. Headache 55: 943-957. CrossRef Medline
Moskowitz MA (1984) The neurobiology of vascular head pain. Ann Neurol 16:157-168. CrossRef Medline

Nees TA, Tappe-Theodor A, Sliwinski C, Motsch M, Rupp R, Kuner R, Weidner N, Blesch A (2016) Early-onset treadmill training reduces mechanical allodynia and modulates calcitonin gene-related peptide fiber density in lamina III/IV in a mouse model of spinal cord contusion injury. Pain 157:687-697. CrossRef Medline

O'Connor TP, van der Kooy D (1988) Enrichment of a vasoactive neuropeptide (calcitonin gene related peptide) in the trigeminal sensory projection to the intracranial arteries. J Neurosci 8:2468-2476. Medline

Palecek J, Palecková V, Dougherty PM, Carlton SM, Willis WD (1992) Responses of spinothalamic tract cells to mechanical and thermal stimulation of skin in rats with experimental peripheral neuropathy. J Neurophysiol 67: 1562-1573. Medline

Price DD, Dubner R, Hu JW (1976) Trigeminothalamic neurons in nucleus caudalis responsive to tactile, thermal, and nociceptive stimulation of monkey's face. J Neurophysiol 39:936-953. Medline

Price DD, Hayes RL, Ruda M, Dubner R (1978) Spatial and temporal transformations of input to spinothalamic tract neurons and their relation to somatic sensations. J Neurophysiol 41:933-947. Medline

Recober A, Kuburas A, Zhang Z, Wemmie JA, Anderson MG, Russo AF (2009) Role of calcitonin gene-related peptide in light-aversive behavior: implications for migraine. J Neurosci 29:8798-8804. CrossRef Medline

Recober A, Kaiser EA, Kuburas A, Russo AF (2010) Induction of multiple photophobic behaviors in a transgenic mouse sensitized to CGRP. Neuropharmacology 58:156-165. CrossRef Medline

Ruscheweyh R, Forsthuber L, Schoffnegger D, Sandkühler J (2007) Modification of classical neurochemical markers in identified primary afferent neurons with Abeta-, Adelta-, and C-fibers after chronic constriction injury in mice. J Comp Neurol 502:325-336. CrossRef Medline

Russo AF (2015) Calcitonin gene-related peptide (CGRP): a new target for migraine. Annu Rev Pharmacol Toxicol 55:533-552. CrossRef Medline

Russo AF, Kuburas A, Kaiser EA, Raddant AC, Recober A (2009) A potential preclinical migraine model: CGRP-sensitized mice. Mol Cell Pharmacol 1:264-270. Medline

Silverman JD, Kruger L (1989) Calcitonin-gene-related-peptide-immunoreactive innervation of the rat head with emphasis on specialized sensory structures. J Comp Neurol 280:303-330. CrossRef Medline

Spencer NJ, Kyloh M, Beckett EA, Brookes S, Hibberd T (2016) Different types of spinal afferent nerve endings in stomach and esophagus identified by anterograde tracing from dorsal root ganglia. J Comp Neurol 524: 3064-3083. CrossRef Medline

Storer RJ, Akerman S, Goadsby PJ (2004) Calcitonin gene-related peptide (CGRP) modulates nociceptive trigeminovascular transmission in the cat. Br J Pharmacol 142:1171-1181. CrossRef Medline

Strassman AM, Raymond SA, Burstein R (1996) Sensitization of meningeal sensory neurons and the origin of headaches. Nature 384:560-564. CrossRef Medline

Stucky NL, Gregory E, Winter MK, He YY, Hamilton ES, McCarson KE, Berman NE (2011) Sex differences in behavior and expression of CGRPrelated genes in a rodent model of chronic migraine. Headache 51:674692. CrossRef Medline

Sun H, Dodick DW, Silberstein S, Goadsby PJ, Reuter U, Ashina M, Saper J, Cady R, Chon Y, Dietrich J, Lenz R (2016) Safety and efficacy of AMG 334 for prevention of episodic migraine: a randomised, double-blind, placebo-controlled, phase 2 trial. Lancet Neurol 15:382-390. CrossRef Medline

Surmeier DJ, Honda CN, Willis WD (1986) Responses of primate spinothalamic neurons to noxious thermal stimulation of glabrous and hairy skin. J Neurophysiol 56:328-350. Medline

Tsai SH, Tew JM, McLean JH, Shipley MT (1988) Cerebral arterial innervation by nerve fibers containing calcitonin gene-related peptide (CGRP): I. Distribution and origin of CGRP perivascular innervation in the rat. J Comp Neurol 271:435-444. CrossRef Medline

Uddman R, Hara H, Edvinsson L (1989) Neuronal pathways to the rat middle meningeal artery revealed by retrograde tracing and immunocytochemistry. J Auton Nerv Syst 26:69-75. CrossRef Medline

Zhang X, Levy D, Kainz V, Noseda R, Jakubowski M, Burstein R (2011) Activation of central trigeminovascular neurons by cortical spreading depression. Ann Neurol 69:855-865. CrossRef Medline 